\title{
Demonstration of Covalent Sidewall Functionalization of Single Wall Carbon Nanotubes by NMR Spectroscopy: Side Chain Length Dependence on the Observation of the Sidewall $\mathrm{sp}^{3}$ Carbons
}

\author{
Liling Zeng, Lawrence B. Alemany, Christopher L. Edwards, and Andrew R. Barron（ $\square ）$
}

Richard E. Smalley Institute for Nanoscale Science and Technology and Department of Chemistry, Rice University, Houston, TX 77005, USA

Received: 7 April 2008/ Revised: 16 May 2008/Accepted: 18 May 2008

CTsinghua Press and Springer-Verlag 2008

\begin{abstract}
Carboxylic acid-functionalized single walled carbon nanotubes (SWNTs) prepared via the reaction of an amino acid, $\mathrm{NH}_{2}\left(\mathrm{CH}_{2}\right)_{n} \mathrm{CO}_{2} \mathrm{H}$ where $n=1$ (glycine, GLY), 5 (6-aminohexanoic acid, AHA), 10 (11-aminoundecanoic acid, AUDA), with fluorinated single walled carbon nanotubes (F-SWNTs) have been characterized by MAS ${ }^{13} \mathrm{C}$ NMR spectroscopy. The ease of observing the aliphatic $\mathrm{CH}_{2}$ groups and the resolution of the signal are dependent on the length of the amino acid's aliphatic chain. We have proposed that where substituent chains are short (making NMR data collection difficult) chemical modification to extend the chain length should alleviate analysis problems. In this regard, we have investigated the esterification of the carboxylic acid termini. The amino acid-functionalized SWNTs were esterified with an appropriate alcohol to ensure parity of the overall substituent length, i.e., GLY-SWNT $\left(\mathrm{C}_{1}\right)+$ 1-dodecanol $\left(\mathrm{C}_{12}\right)=$ DOD-GLY-SWNT (1), AHA-SWNT $\left(\mathrm{C}_{5}\right)+$ 1-octanol $\left(\mathrm{C}_{8}\right)=$ OCT-AHA-SWNT (2), and AUDA-SWNT $\left(\mathrm{C}_{10}\right)+1$-propanol $\left(\mathrm{C}_{3}\right)=$ PRO-AUDA-SWNT (3). The ${ }^{13} \mathrm{C}$ NMR shift for the $\mathrm{sp}^{3}$ nitrogen-substituted carbon atoms of the SWNT sidewall is observed at $\delta \approx 75$ ppm. Increasing the length of SWNT sidewall functional groups enhances the ability to observe the sidewall $\mathrm{sp}^{3}$ carbon. The methylene carbon signal intensity is less attenuated in the dipolar dephasing spectrum of the ester-functionalized SWNTs than their associated amino acid derivatives, suggesting more motional freedom of the side chain in the solid state. The confirmation of the dipolar dephasing spectral effects was assisted by the characterization of the ester of AUDA-SWNT with 1,3-propanediol: PPD-AUDA-SWNT (4).
\end{abstract}

\section{KEYWORDS}

Single walled carbon nanotube (SWNT), nuclear magnetic resonance (NMR), esterification, amino acid, functionalization

\section{Introduction}

The technological advances in various microscopies have, in part, enabled the characterization of nanomaterials. Despite this ability to "image" individual nanoparticles, there are still often significant questions with regard to their characterization. One area where ambiguity is often

Address correspondence to arb@rice.edu 
observed is whether a substituent around a nanoparticle is covalently bound rather than simply adsorbed onto the surface. The determination of bonding interactions in molecular compounds has traditionally been accomplished by spectroscopic methods, often in combination with structural and computational methods [1-5]. We have previously applied a combination of spectroscopic methods and comparisons with model systems to demonstrate the presence and mode of covalent attachment of substituents to ceramic nanoparticles [6-8]. As part of our investigations into the application of single walled carbon nanotubes (SWNTs) in biological environments [9-11], we have recently undertaken a solid state neclear magnetic resonance (NMR) study of sidewallfunctionalized SWNTs in part to confirm the covalent attachment of the sidewall substituents $[12,13]$.

Our initial studies focused on the characterization of fluorinated single walled carbon nanotubes (F-SWNTs) because of the high level of substitution $(\mathrm{C}: \mathrm{F}=2.1: 1)$ and lack of organic substituents making them ideal for identifying the sidewall $\mathrm{sp}^{3}$ carbon atoms [12]. The ${ }^{13} \mathrm{C}$ NMR shift for the $\mathrm{sp}^{3}$ fluorinesubstituted $(\mathrm{C}-\mathrm{F})$ carbon atoms of the SWNT sidewall is observed at $\delta=83.5 \mathrm{ppm}$. This apparently unusual shift, as compared to most other tertiary alkyl fluorides, was confirmed to be due to the C-F moieties from $a b$ initio calculations on an eighty-carbon fragment of the 5,5 (armchair) SWNT and is in good agreement with the predominance of 1,2-addition rather than 1,4-addition of fluorine. The excellent correlation between experimental observation [12] and theoretical prediction [14] offers a check on spectral assignments in more complex systems.

As would be expected, the low solubility and large size (and hence slow tumbling in solution) limited useful solution NMR studies $[15,16]$. Prior solid state NMR studies have proved useful for the observation of substituents [16-20], but, unfortunately, usually less so with regard to the observation of the important quaternary $\mathrm{sp}^{3}$ sidewall carbon atoms [13] that would provide definitive evidence for covalent attachment. In one report, the quaternary sidewall carbon atoms were clearly detected by obtaining cross polarization magic angle spinning (CPMAS) spectra with and without a dephasing delay before
FID acquisition [20]. In this present study, we have followed this approach. Our results demonstrate that the length of an organic substituent has a significant effect on the observation of quaternary $\mathrm{sp}^{3}$ sidewall carbon atoms, and an unusual mobility is observed for long chain substituents in the solid state. These results are described herein.

\section{Experimental}

Raw HiPco SWNTs produced at Rice University were purified to remove iron and other impurities by a previously described procedure [21]. After purification, the impurities from the catalyst for synthesizing the SWNTs were removed as shown in the thermogravimetric analysis (TGA) data. Also, the X-ray photoelectron spectroscopy (XPS) shows the iron concentration in purified SWNTs was below $0.01 \%$. Subsequently, the purified SWNTs were directly fluorinated to a $\mathrm{C} / \mathrm{F}$ ratio of approximately 3:1 at $150{ }^{\circ} \mathrm{C}$ by a method reported previously [22]. The F-SWNTs were functionalized with glycine, 6-aminohexanoic acid, and 11-aminoundecanoic acid to prepare amino acid-functionalized SWNTs [9]. Glycine, 6-aminohexanoic acid, 11-aminoundecanoic acid, 1,3-dicyclohexylcarbodiimide (DCC), 1-propanol, 1,3-propanediol, 1-octanol, and 1-dodecanol were obtained from Aldrich and used as received. All solvents were purchased from Fisher Chemical and used as received, except dimethylformamide (DMF) that was distilled under reduced pressure with $\mathrm{CaSO}_{4}$ before use. Attenuated total reflectance IR spectroscopy (ATR-IR; 4000-600 $\mathrm{cm}^{-1}$ ) of solids was obtained using a Nicolet Nexus 670 FTIR spectrometer with a diamond window. Thermal analysis was performed on a TA Instruments SDT 2960 using platinum pans. Raman Spectroscopy was performed on a Renishaw Raman microscope. Atomic force microscopy (AFM) was performed on a digital instruments nanoscope IIIA microscope in tapping mode with $125 \mu \mathrm{m}$ TESP tips. Transmission electron microscopy (TEM) images were done on a Jeol 2010 Electron Microscope.

Calculations were carried out using the Gaussian 03, revision C.02 (Windows version), suite of programs [23]. Geometry optimization on the $\mathrm{C}_{80} \mathrm{H}_{20}$ 
and the functionalized fragment was performed by HF/STO-3G. Subsequently the ${ }^{13} \mathrm{C}$ nuclear shielding was computed by HF/3-21G. To determine the NMR shift values, the NMR shielding tensor of TMS at the same level of theory was calculated. The difference between the carbon magnetic shielding in TMS and SWNT fragment was the calculated ${ }^{13} \mathrm{C}$ NMR shift in the SWNT fragment.

\section{$1.1{ }^{13} \mathrm{C}$ NMR spectroscopy}

${ }^{13} \mathrm{C}$ MAS spectra were obtained on a Bruker AVANCE200 NMR spectrometer $\left(50.3 \mathrm{MHz}{ }^{13} \mathrm{C}, 200.1 \mathrm{MHz}{ }^{1} \mathrm{H}\right)$, as previously described [12, 13, 19, 20, 24]. Chemical shifts are reported relative to the carbonyl carbon of glycine defined as $176.46 \mathrm{ppm}$. Basic ${ }^{1} \mathrm{H}^{-13} \mathrm{C}$ CPMAS spectra were obtained with a 4-mm outer diameter rotor spinning at $7 \mathrm{kHz}, 1-\mathrm{ms}$ contact time, $29.3-\mathrm{ms}$ FID, and 5-s relaxation delay. The dipolar dephasing spectra differed from the basic ${ }^{1} \mathrm{H}-{ }^{13} \mathrm{C}$ CPMAS spectra in that after $\mathrm{CP}$, two dephasing periods of equal length (usually $25 \mu \mathrm{s}$ each) with a $180^{\circ}{ }^{13} \mathrm{C}$ refocusing pulse in the middle were used before FID acquisition in order to eliminate or severely attenuate signals from ${ }^{13} \mathrm{C}$ nuclei experiencing strong ${ }^{13} \mathrm{C}-{ }^{1} \mathrm{H}$ dipole-dipole interactions. Direct ${ }^{13} \mathrm{C}$ pulse MAS spectra were obtained with the $4 \mathrm{~mm}$ rotor spinning at 11 or $12 \mathrm{kHz}, 4.3-\mu \mathrm{s} 90^{\circ}{ }^{13} \mathrm{C}$ pulse, 20.5-ms FID, and 10-s relaxation delay. All FIDs of functionalized SWNTs were processed with $50 \mathrm{~Hz}(1 \mathrm{ppm})$ of line broadening. The number of scans used to obtain each spectrum is indicated in the figure captions. Unless otherwise noted, enough of each functionalized SWNT was available to fill the rotor.

Standard CPMAS and dipolar dephasing spectra were also obtained on simple compounds (glycine, $\mathrm{N}$-tritylglycine, 6-aminohexanoic acid, 11-aminoundecanoic acid, stearic acid, and n-propyl stearate) for reference data. The reference compounds were studied with the same CPMAS and dipolar dephasing parameters to allow direct comparison with the functionalized SWNTs but with usually slightly less than $7 \mathrm{kHz}$ MAS to ensure that the upfield spinning sideband of the carbonyl signal did not overlap any of the aliphatic signals in the reference compound. However, ambient spectra of $n$-propyl stearate were obtained with only $3.0 \mathrm{kHz}$ MAS to minimize frictional heating effects [25] because this solid melts at $29^{\circ} \mathrm{C}$. Spectra of $n$-propyl stearate with $6.2 \mathrm{kHz}$ MAS were also obtained at about $-35^{\circ} \mathrm{C}$, with cooling achieved by passing nitrogen gas at $400 \mathrm{~L} / \mathrm{h}$ through a 12-turn heat exchanger immersed in liquid nitrogen before entering the probe Dewar and flowing up to the stator. The sample temperature was determined by calibrating with lead nitrate under the same conditions [25]. FIDs from the various experiments with stearic acid and $n$-propyl stearate were processed with only $5 \mathrm{~Hz}(0.1 \mathrm{ppm})$ of line broadening in light of the high signal-to-noise $(\mathrm{S} / \mathrm{N})$ that could readily be achieved (only 128 scans for each spectrum in Fig. S-1; only 200 scans for each spectrum in Figs. S-2 and S-3, Supplementary Material). The sinc wiggles in the spectra of stearic acid (Fig. S-1) and $n$-propyl stearate (Figs. S-2 and S-3) result from truncated FIDs.

\subsection{DOD-GLY-SWNTs (1)}

GLY-SWNTs (ca. $30 \mathrm{mg}$ ) were sonicated in dry DMF (300 $\mathrm{mL})$ for $30 \mathrm{~min}$, resulting in a dark solution with complete dispersion. DCC (41.4 mg) and 1-dodecanol (37.3 mg) were added to the solution. The reaction mixture was stirred under argon for $24 \mathrm{~h}$ at room temperature. After the reaction, the solution was vacuum filtered through a $0.2-\mu \mathrm{m}$ pore size membrane, and flushed with large amount of acetone, toluene and chloroform to ensure complete removal of unreacted 1-dodecanol, reaction catalyst, by-product, and solvent. Then the sample was dried overnight under vacuum at $70{ }^{\circ} \mathrm{C}$. OCT-AHA-SWNTs (2), PRO-AUDA-SWNTs (3), and PPD-AUDASWNTs (4) were prepared using the appropriate alcohol: 1-octanol, 1-propanol, and 1,3-propanediol, respectively.

\section{Results and discussion}

Carboxylic acid-functionalized SWNTs were prepared via the reaction of an amino acid, $\mathrm{NH}_{2}\left(\mathrm{CH}_{2}\right)_{n} \mathrm{CO}_{2} \mathrm{H}$, with F-SWNTs (Scheme 1) [9]. Three hydrocarbon side chain lengths were prepared from glycine (GLY, $n=1$ ), 6-aminohexanoic acid (AHA, $n=5$ ), and 11-aminoundecanoic acid (AUDA, $n=10$ ). In each case, the $\mathrm{C}_{\mathrm{SWNT}}$ to substituent ratio is determined by 


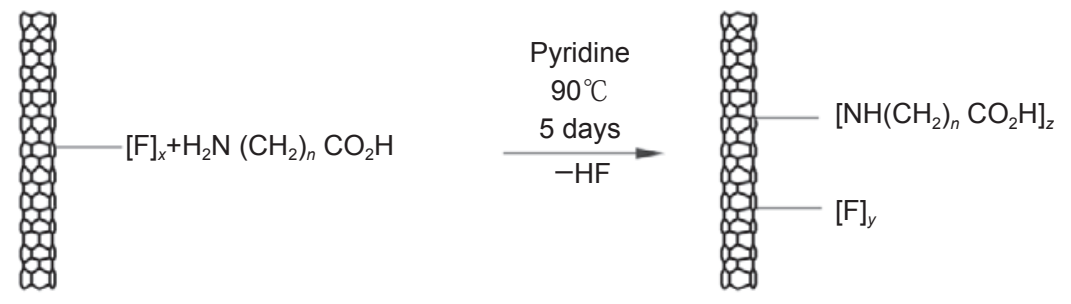

$n=1$ (GLY-SWNT), 5(AHA-SWNT), 10 (AUDA-SWNT) $x>>y$ and $x>y+z$

Scheme 1 Synthesis of amino acid-functionalized SWNTS

XPS to be in the range between 18:1 and 15:1 [9]. All amino acid-functionalized SWNTs were prepared from the same batch of F-SWNTs in order to enable meaningful comparisons of the resulting materials. In addition, any iron from the catalyst used to prepare the starting HiPco SWNTs was removed during the synthesis of the F-SWNTs and subsequent reactions.

The ${ }^{13} \mathrm{C}$ MAS NMR spectra were collected for each of the amino acid-functionalized SWNTs using three different experiments: (a) direct $90^{\circ}$ pulse ${ }^{13} \mathrm{C},(\mathrm{b}){ }^{1} \mathrm{H}^{-}$ ${ }^{13} \mathrm{C}$ cross polarization to enhance (highest signal/ noise) the signals of carbons that are bonded to or near protons, and (c) a cross-polarization experiment with a dephasing period inserted before FID acquisition to attenuate signals that are from nuclei that are directly bonded to ${ }^{1} \mathrm{H}$, in particular $-\mathrm{CH}^{-}$and $-\mathrm{CH}_{2}{ }^{-}$.

As may be expected, each of the direct $90^{\circ}$ pulse ${ }^{13} \mathrm{C}$ MAS NMR spectra (Figs. 1(a), 2(a), and 3(a)) show the signal associated with the $\mathrm{sp}^{2}$ carbons of the SWNT (121-122 ppm), consistent with previous results [12]. However, the aliphatic signals in these three spectra vary greatly in their intensities. No signal for the aliphatic $\left(\mathrm{CH}_{2}\right)$ carbon is observed for GLY-SWNT (Fig. 1(a)), while a weak, broad signal is seen for the various $\mathrm{CH}_{2}$ carbon atoms in AHASWNT (Fig. 2(a)), even though there was less material in the $4 \mathrm{~mm}$ rotor. In contrast, a proportionately much stronger aliphatic signal is observed from a full rotor of AUDA-SWNT (Fig. 3(a)) (vide supra); lengthening the relaxation delay from $10 \mathrm{~s}$ to $30 \mathrm{~s}$ had no noticeable effect. In addition, the spectrum for AUDA-SWNT clearly exhibits a carbonyl signal.

The ${ }^{1} \mathrm{H}^{-13} \mathrm{C}$ CPMAS spectra show greatly differing enhancements in the signals of carbons that are bonded to protons. The $\mathrm{CH}_{2}$ group in GLY-SWNT gives a barely detectable broad hump (Fig. 1(b)). In contrast, the CPMAS spectrum for AHA-SWNT clearly shows a signal for the various $\mathrm{CH}_{2}$ carbon atoms (Fig. 2(b)), even though there was not enough material available to fill the rotor (vide supra). In addition, aliphatic signal intensity is also clearly present downfield of the region where the $\mathrm{CH}_{2}$ signals would be expected. The broad signal from about 140-190 ppm encompasses the range expected for a carboxylic acid $\left(\mathrm{CO}_{2} \mathrm{H}\right)$ group, such as that associated with the amino acid.

The CPMAS spectrum for AUDA-SWNT shows an exceptionally high signal-to-noise $(\mathrm{S} / \mathrm{N})$ for a functionalized SWNT (Fig. 3(b)), and only a small amount of ${ }^{1} \mathrm{H}$ and ${ }^{13} \mathrm{C}$ probe tuning and matching adjustments (relative to glycine) was required. As
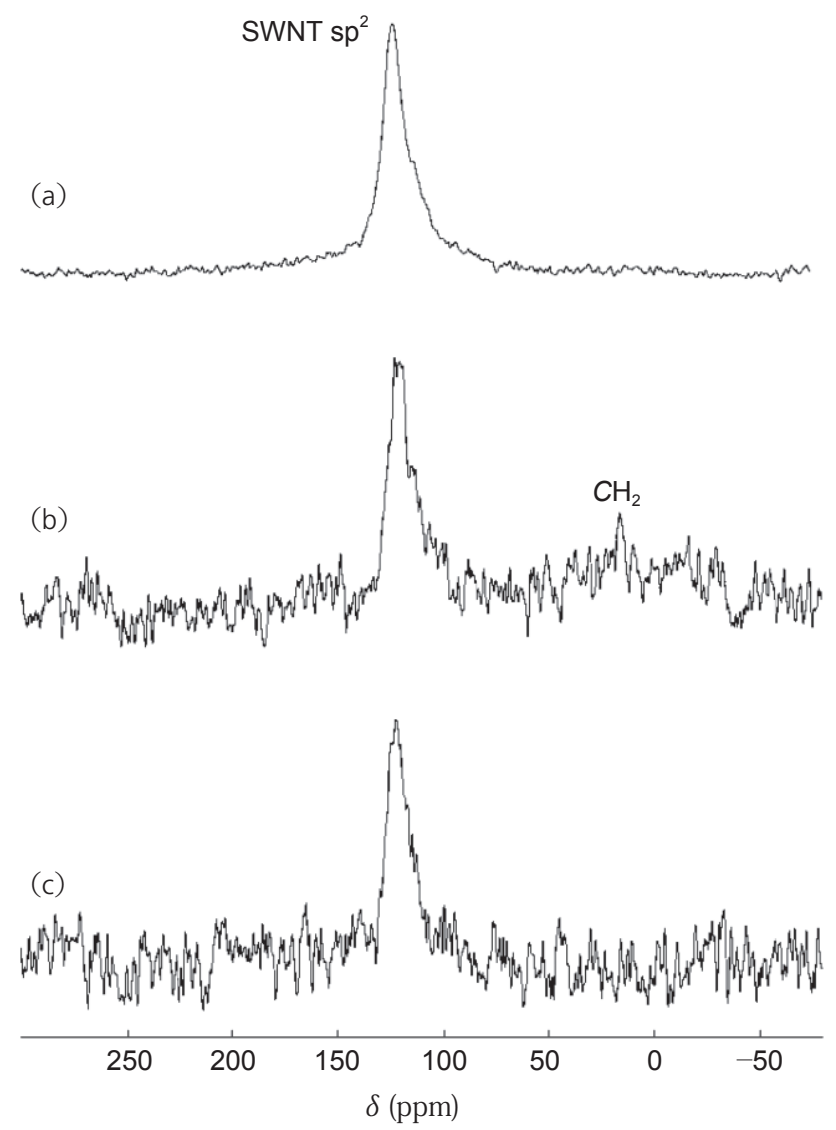

Figure 1 GLY-SWNT: (a) $90^{\circ}{ }^{13} \mathrm{C}$ pulse MAS spectrum (8600 scans), (b) ${ }^{1} \mathrm{H}-{ }^{13} \mathrm{C}$ CPMAS spectrum (25600 scans), and (c) ${ }^{1} \mathrm{H}-{ }^{13} \mathrm{C}$ CPMAS spectrum with a 50- $\mu$ s dephasing interval before FID acquisition (25 600 scans) 

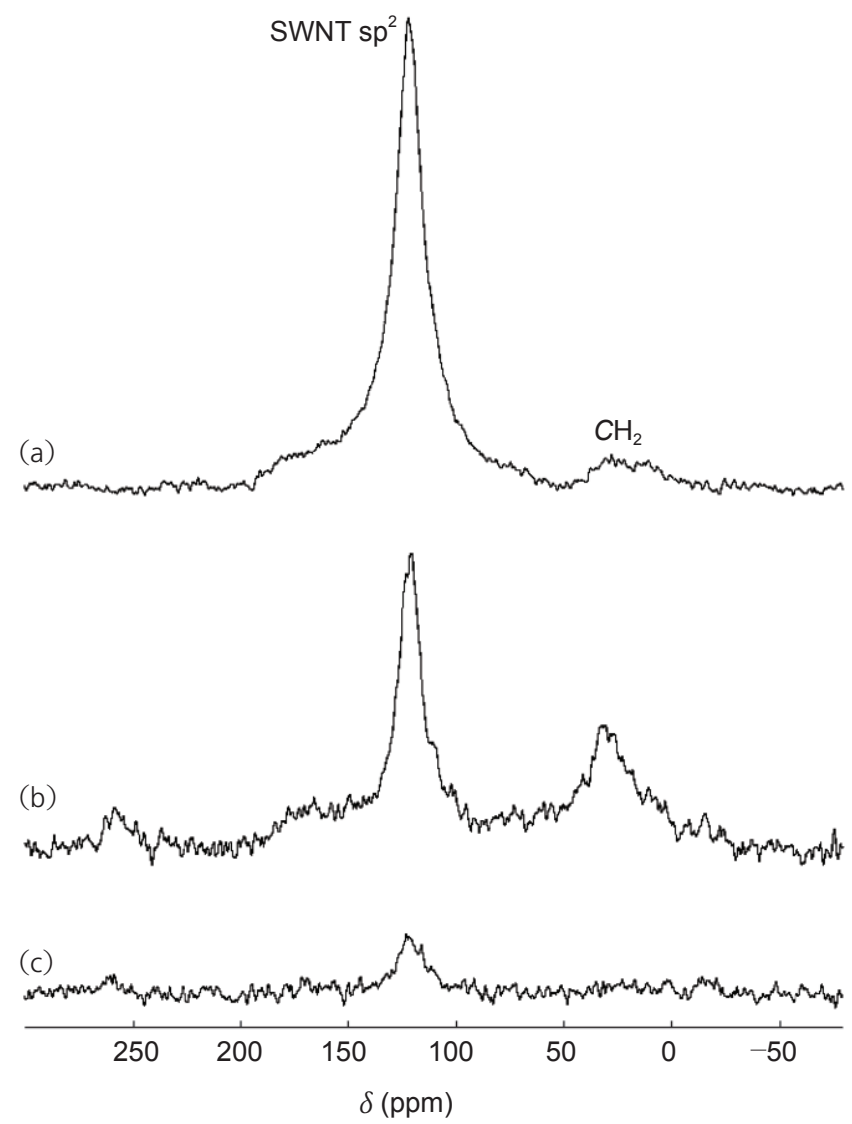

Figure 2 AHA-SWNT, only a partially filled rotor: (a) $90^{\circ}{ }^{13} \mathrm{C}$ pulse MAS spectrum (20 400 scans), (b) ${ }^{1} \mathrm{H}-{ }^{13} \mathrm{C}$ CPMAS spectrum (25 400 scans), and (c) ${ }^{1} \mathrm{H}-{ }^{13} \mathrm{C}$ CPMAS spectrum with a $50-\mu$ s dephasing interval before FID acquisition (25 400 scans)

may be seen from Fig. 3(b), the methylene signal is very strong, while the SWNT $\mathrm{sp}^{2}$ signal is weak. In addition, there is a clearly recognizable $\mathrm{CO}_{2} \mathrm{H}$ signal (about 175 ppm).

Even though the three functionalized SWNT samples were prepared from the same batch of SWNTs and were functionalized to similar extents (i.e., similar $\mathrm{C}_{\mathrm{SWNT}}$ :substituent ratio), these samples exhibited significantly different probe tuning characteristics relative to the glycine standard used to check spectrometer performance before each sample was studied. The AUDA-SWNT sample required relatively little adjusting of the tuning and matching for the probe's ${ }^{13} \mathrm{C}$ and ${ }^{1} \mathrm{H}$ channels; the AHA-SWNT sample required more adjusting, particularly for the ${ }^{1} \mathrm{H}$ channel; and the GLY-SWNT sample required still more adjusting for each channel, particularly for the matching. It is not clear if the favorable probe tuning
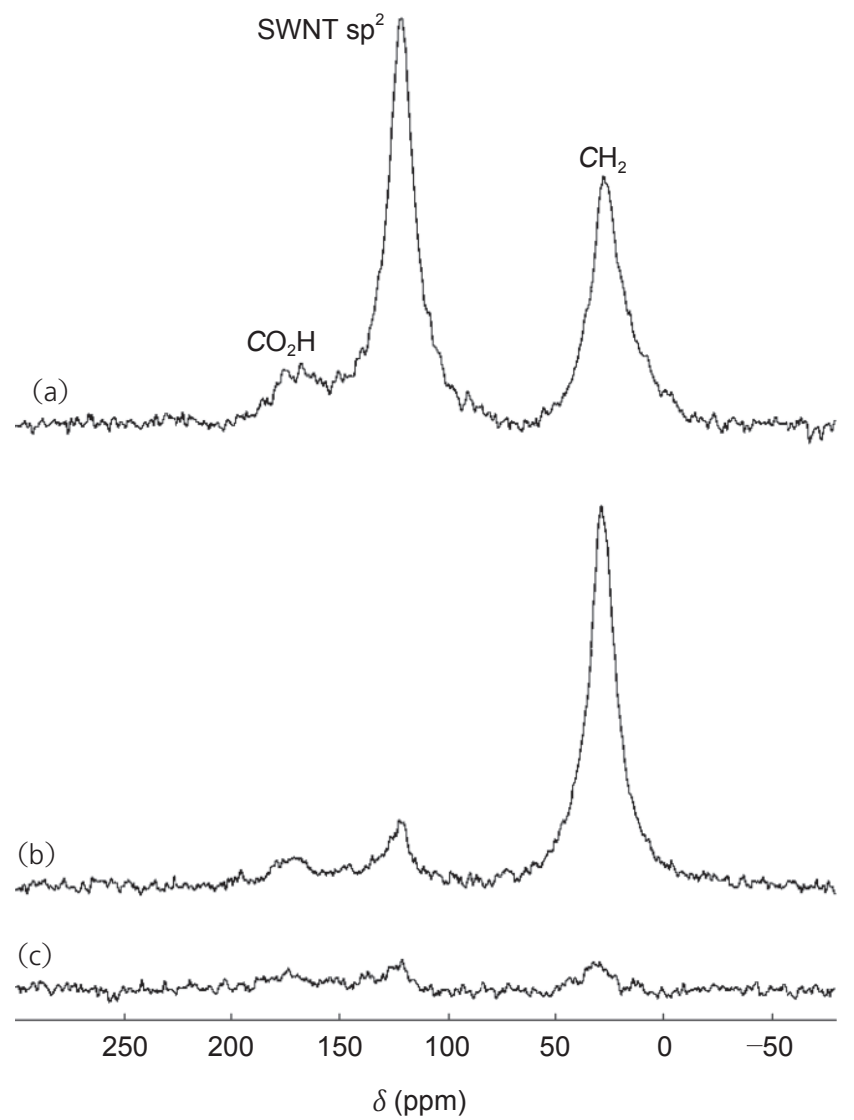

Figure 3 AUDA-SWNT: (a) $90^{\circ}{ }^{13} \mathrm{C}$ pulse MAS spectrum (8360 scans), (b) ${ }^{1} \mathrm{H}-{ }^{13} \mathrm{C}$ CPMAS spectrum (15000 scans), and (c) ${ }^{1} \mathrm{H}-$ ${ }^{13} \mathrm{C}$ CPMAS spectrum with a $50-\mu \mathrm{s}$ dephasing interval before FID acquisition (15000 scans)

characteristics of the AUDA-SWNT sample result from the higher percentage of mass from the side chains, from more effective isolation of the nanotubes from each other by the longer side chains, or from a combination of both factors. Another ${ }^{13} \mathrm{C}$ MAS NMR study of nanotubes also indicated "probe tuning was significantly affected" [26].

Comparing the CPMAS spectra obtained from full rotors of GLY-SWNT and AUDA-SWNT (Figs. 1(b) and 3(b)) shows that the signal-to-noise of the AUDASWNT sample is much higher than might be expected from having ten $\mathrm{CH}_{2}$ groups instead of one $\mathrm{CH}_{2}$ group. If the relatively short side chains of GLY-SWNT are often not near each other, then ${ }^{1} \mathrm{H}$ spin diffusion may be inefficient and ${ }^{1} \mathrm{H}$ spin-lattice relaxation correspondingly slow, i.e., $T_{1}(\mathrm{H})$ would be long, which in turn would limit the amount of ${ }^{13} \mathrm{C}$ signal intensity that could be generated in a $\mathrm{CP}$ experiment 
with a relaxation delay of only a few seconds. To try to test this hypothesis, CPMAS spectra were obtained on GLY-SWNT under identical conditions except for the length of the relaxation delay. Lengthening the delay from $5 \mathrm{~s}$ to $20 \mathrm{~s}$ only modestly increased the $\mathrm{S} / \mathrm{N}$ ratio. Additional work would be required to pursue this aspect in more detail.

As expected $[27,28]$, the $50-\mu$ s dephasing interval in the dipolar dephasing experiment greatly attenuates or eliminates the methylene carbon signals in the functionalized SWNTs. In the GLY-SWNT sample, the barely detectable broad hump for the $\mathrm{CH}_{2}$ group in the standard CPMAS spectrum (Fig. 1(b)) is gone (Fig. 1(c)). Similarly, in the AHA-SWNT sample, the signal for the various $\mathrm{CH}_{2}$ carbons in the standard CPMAS spectrum (Fig. 2(b)) is gone (Fig. 2(c)). In the AUDA-SWNT sample, the intense signal for the various $\mathrm{CH}_{2}$ carbons in the standard CPMAS spectrum (Fig. 3(b)) is strongly attenuated, but not eliminated (Fig. 3(c)). That any $\mathrm{CH}_{2}$ carbon signal intensity remains is noteworthy because with the same dephasing interval, the $\mathrm{CH}_{2}$ carbon signal completely decays in the corresponding amino acids, $\mathrm{H}_{2} \mathrm{~N}\left(\mathrm{CH}_{2}\right)_{n} \mathrm{CO}_{2} \mathrm{H}, n=1$, 5, or 10 , and in $\left(\mathrm{C}_{6} \mathrm{H}_{5}\right)_{3} \mathrm{C}-\mathrm{NHCH}_{2} \mathrm{CO}_{2} \mathrm{H}$. Thus, the methylene carbons in AUDA-SWNT appear to have somewhat more motional freedom than in the corresponding model compound and than in the shorter chain AHA-SWNT and GLY-SWNT. The longer methylene chains in AUDA-SWNT may be better at separating the nanotubes and creating more space in which the chains can flop around (particularly towards the carboxyl end) in this disordered solid. In contrast, in the well defined organic compound stearic acid $\left[\mathrm{CH}_{3}\left(\mathrm{CH}_{2}\right)_{16} \mathrm{CO}_{2} \mathrm{H}\right]$, the methylene carbon signals completely decay after a $50-\mu$ s dephasing interval (Supplementary Material, Fig. S-1).

The nanotube $\mathrm{sp}^{2}$ carbon signal intensity would be expected to decay much more slowly. This signal shows a negligible change in the GLY-SWNT sample (Fig. 1(c)) but is significantly attenuated in the AHASWNT and AUDA-SWNT samples (Figs. 2(c) and 3(c)). The dephasing delay eliminates the broad, deshielded $\mathrm{sp}^{2}$ and $\mathrm{sp}^{3}$ signals in the standard CPMAS spectrum of AHA-SWNT (Fig. 2(b)), but some carboxyl intensity remains for AUDA-SWNT (Fig. 3(c)). In the dipolar dephasing experiment, the significant attenuation of the nanotube $\mathrm{sp}^{2}$ carbon signal in the AHA-SWNT and AUDA-SWNT samples suggests that the sum of the ${ }^{13} \mathrm{C}^{-1} \mathrm{H}$ dipole-dipole interactions over all the protons in these samples is appreciable.

A signal is not clearly detected for the nanotube quaternary $\mathrm{sp}^{3}$ carbon bonded to nitrogen in any of Figs. 1(c), 2(c), or 3(c). This signal, which would clearly be expected downfield of the signal from the methylene carbons, would be broadened or split because it is bound to ${ }^{14} \mathrm{~N}$, thus making it more difficult to detect [26, 29-32].

Comparing the spectra in Figs. 1-3 indicates that ${ }^{13} \mathrm{C}$ MAS NMR can more readily characterize the amino acid-functionalized SWNTs if the substituent is longer: with the AUDA-SWNT sample, the S/N is clearly higher in both the standard CPMAS and direct $90^{\circ}{ }^{13} \mathrm{C}$ pulse spectra, and the amount of detail in the dipolar dephasing spectrum is greater. Thus, it appeared that where substituent chains are short and limit the amount of NMR information that can be obtained, chemical functionalization to extend the chain length might be beneficial.

In this regard, we have investigated the esterification of the carboxylic acid termini. In order to compare the effect of chain length as opposed to the esterification reaction itself, each amino acid-functionalized SWNT was esterified with an appropriate alcohol to ensure parity of the overall substituent length, i.e., GLY-SWNT was reacted with 1-dodecanol $\left(\mathrm{C}_{1}+\mathrm{C}_{12}\right)$, AHA-SWNT was reacted with 1-octanol $\left(C_{5}+C_{8}\right)$, and AUDASWNT was reacted with 1-propanol $\left(C_{10}+C_{3}\right)$. The esterification reaction was carried out in DMF using a 1,3-dicyclohexylcarbodiimide (DCC) catalyst (Scheme 2) [33] followed by careful washing to ensure complete removal of unreacted alcohol, catalyst, and solvent (see Experimental section).

The Raman spectra of each amino acid-functionalized SWNTs and their associated ester products (1-3) are shown in Fig. 4. As may be seen, there is little difference in the $D: G$ ratios between the amino acid and associated ester derivatives. This suggests that no additional functional groups have been added per SWNT and that any reactivity has not resulted in removal of the amino acid linkages. In contrast, the IR spectra show the expected increase in the intensity 


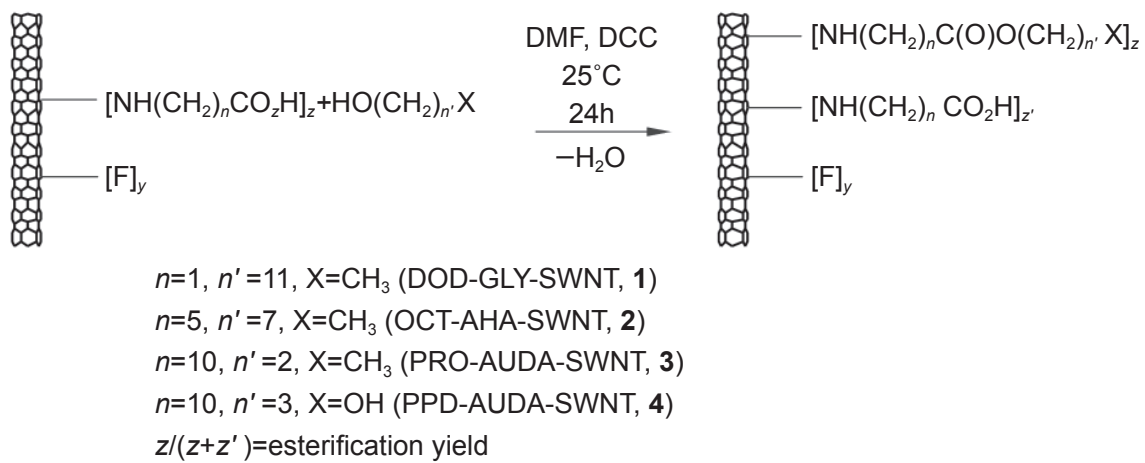

Scheme 2 Esterification of amino acid-SWNTs

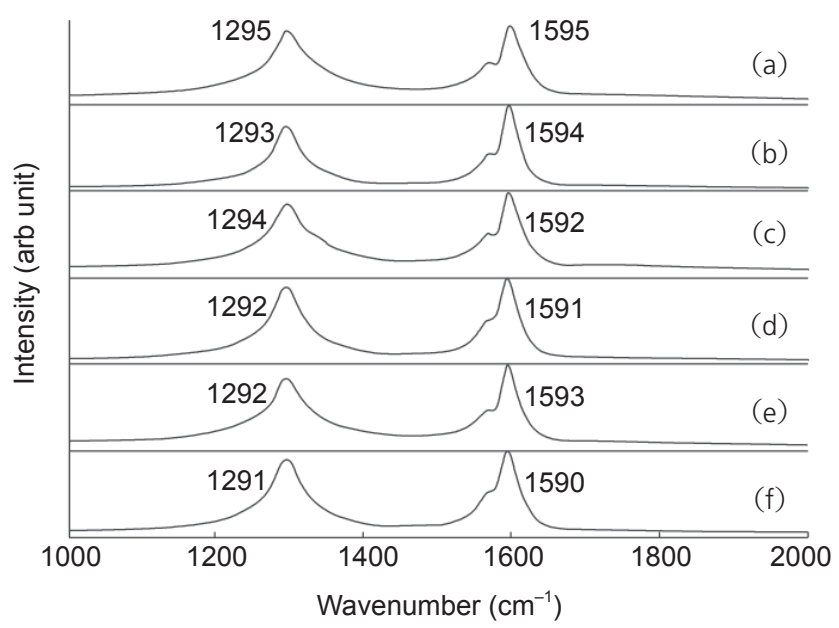

Figure 4 Raman spectra of (a) GLY-SWNTs, (b) DOD-GLY-SWNTS (1), (c) AHA-SWNTs, (d) OCT-AHA-SWNTS (2), (e) AUDA-SWNTS, and (f) PRO-AUDA-SWNTS (3), showing the similarity in D:G ratio between the amino acid and associated ester derivatives

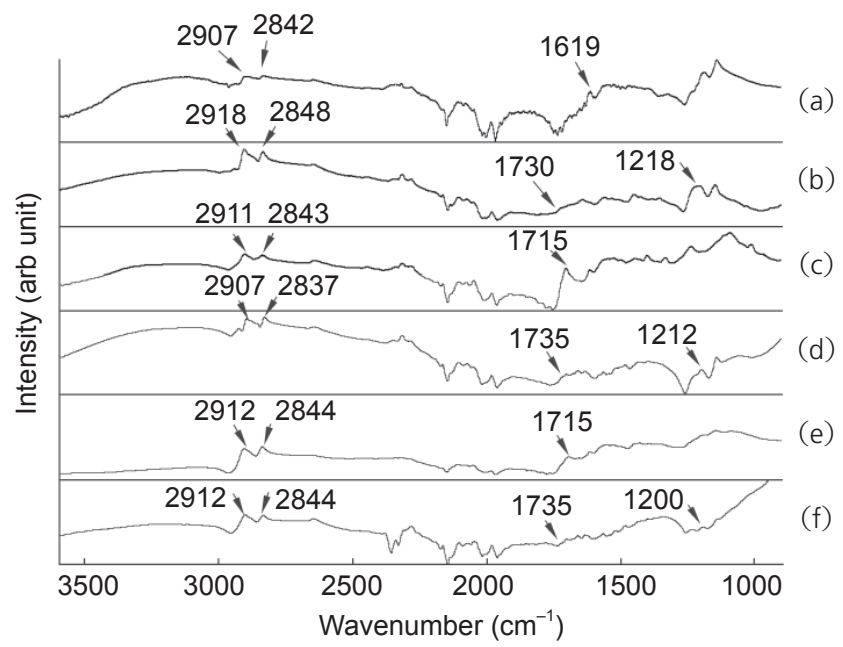

Figure 5 IR spectra of (a) GLY-SWNTS, (b) DOD-GLY-SWNTs (1), (c) AHA-SWNTs, (d) OCT-AHA-SWNTs (2), (e) AUDA-SWNTs, and (f) PROAUDA-SWNTS (3) for the aliphatic $v(\mathrm{C}-\mathrm{H})$ stretch, consistent with the increased organic content after esterification (Fig. 5). This is particularly apparent for the GLY-SWNT vs DOD-GLYSWNT (1). In addition to the increase in the relative intensity of the aliphatic stretch, each of the ester derivatives shows peaks at ca. $1200 \mathrm{~cm}^{-1}$ and $1735 \mathrm{~cm}^{-1}$ consistent with the ester's "-C(O)-O-" and $\mathrm{C}=\mathrm{O}$ groups.

The thermogravimetric analysis (TGA) of each sample shows a steady mass loss between 200 and $600{ }^{\circ} \mathrm{C}$ in a manner typical of sidewall functionalization. The extent of sidewall functionalization is often estimated from the relative mass loss associated with the TGA; however, in the present case, a comparison between the parent amino acidfunctionalized SWNT and its ester counterpart provides a measure of the esterification yield, i.e., how many of the possible carboxylic acid groups have been esterified. Figure 6 shows a representative comparison between GLY-SWNT and DOD-GLYSWNT (1). Based upon the TGA, the esterification yields can be calculated: DOD-GLY-SWNT (35\%), OCT-AHA-SWNT (70\%), and PRO-AUDASWNT (80\%). The yield of DOD-GLY-SWNT can be improved by repeated esterification reactions; however, the original yield is sufficient for the ${ }^{13} \mathrm{C}$ NMR study (see below).

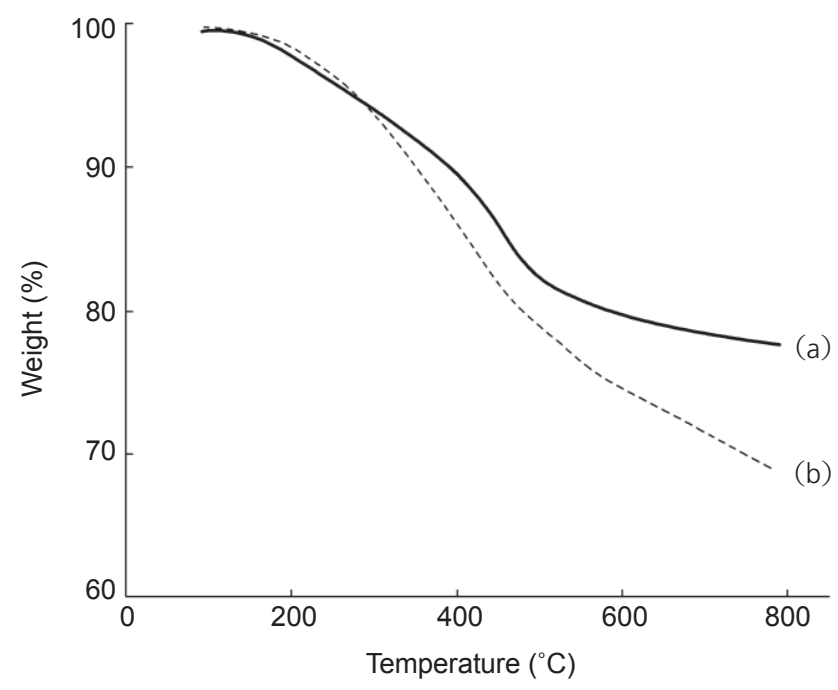

Figure 6 TGA of (a) GLY-SWNT and (b) DOD-GLY-SWNT (1) 
Transmission electron microscopy (TEM) confirms the presence of surface-roughened esterified SWNTs (Fig. 7), although it is difficult to discern any significant difference with the parent amino acidfunctionalized SWNTs. Figure 8 shows representative atomic force microscopy (AFM) image and height measurements of a single tube of OCT-AHA-SWNTs (2) confirming the presence of individual SWNTs and showing the presence of regions of functionalization along the SWNT. We have previously shown [9] that the measured heights of the functionalized regions for AHA-SWNTs (ca. $2.0 \mathrm{~nm}$ ) as compared to the SWNT diameter (ca. $1 \mathrm{~nm}$ ) are consistent with the calculated length of $\mathrm{N}(\mathrm{H})\left(\mathrm{CH}_{2}\right)_{5} \mathrm{CO}_{2} \mathrm{H}$ (molecular modeling with Chem 3D) in an extended conformation (1 nm). The cross sectional height measurement of the OCTAHA-SWNT in Fig. 8 shows three distinct regions. First, is a region associated with the unfunctionalized SWNT $(0.83 \mathrm{~nm})$; second, is a region consistent with the amino acid, $\mathrm{N}(\mathrm{H})\left(\mathrm{CH}_{2}\right)_{5} \mathrm{CO}_{2} \mathrm{H}$, functionalization $(1.7 \mathrm{~nm})$; and third, is a region with a height of $2.6 \mathrm{~nm}$ (Fig. 8). The latter height is consistent with the calculated length of $\mathrm{N}(\mathrm{H})\left(\mathrm{CH}_{2}\right)_{5} \mathrm{C}(\mathrm{O}) \mathrm{O}\left(\mathrm{CH}_{2}\right)_{7} \mathrm{CH}_{3}$ in an extended conformation (1.9 nm). Based upon the foregoing, the analytical data is consistent with the esterification of the amino acid-functionalized SWNTs, extending the sidewall functional groups' chain length.

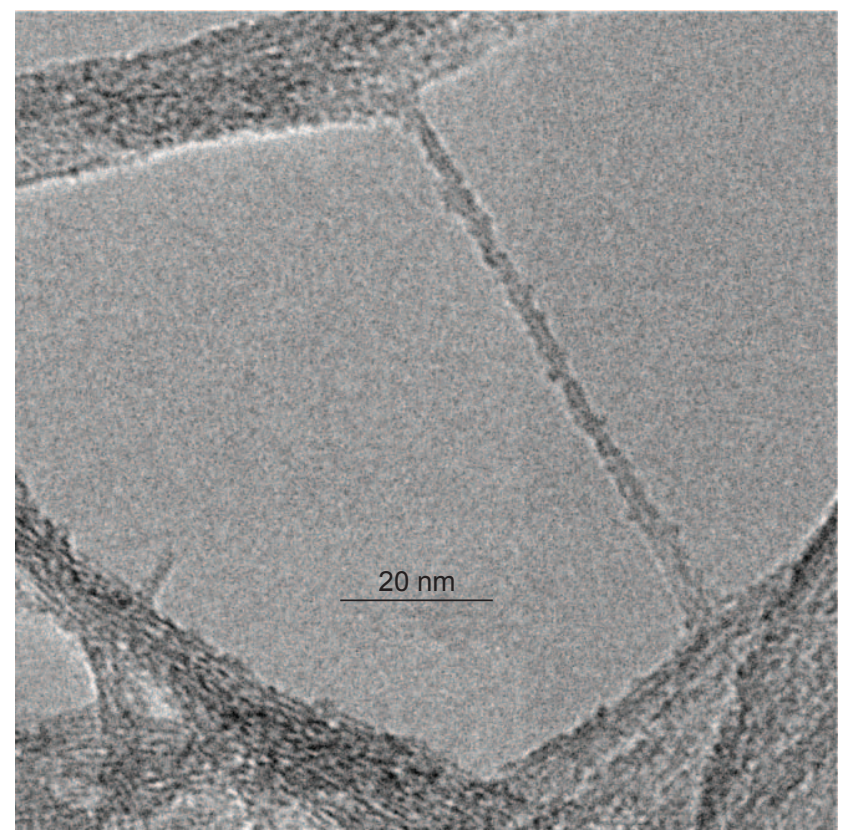

Figure 7 TEM image of OCT-AHA-SWNTS (2)
As with the amino acid-functionalized SWNTs, their ester derivatives were characterized by ${ }^{13} \mathrm{C}$ MAS NMR spectra using (a) direct $90^{\circ}$ pulse ${ }^{13} \mathrm{C},(\mathrm{b}){ }^{1} \mathrm{H}^{-}$ ${ }^{13} \mathrm{C}$ CPMAS, and (c) dipolar dephasing experiments. It is worth noting that much less probe tuning and matching adjustment is needed for DOD-GLY-SWNT (1) than for GLY-SWNT. This is consistent with the observation that tuning is dependent on the chain lengths of the substituents.

As may be expected given the greater number of $\mathrm{CH}_{2}$ groups, the signal associated with the aliphatic $\left(\mathrm{CH}_{2}\right)$ carbon is much more clearly observed in both the direct $90^{\circ}$ pulse ${ }^{13} \mathrm{C}$ MAS spectrum and the ${ }^{1} \mathrm{H}^{-13} \mathrm{C}$ CPMAS spectrum of $\mathbf{1}$ (Figs. 9(a) and (b), respectively) than in the corresponding spectra of GLY-SWNT (Figs. 1(a) and (b)). Unlike GLY-SWNT (Fig. 1(c)), the dipolar dephasing spectrum of DODGLY-SWNT shows some intensity for the aliphatic
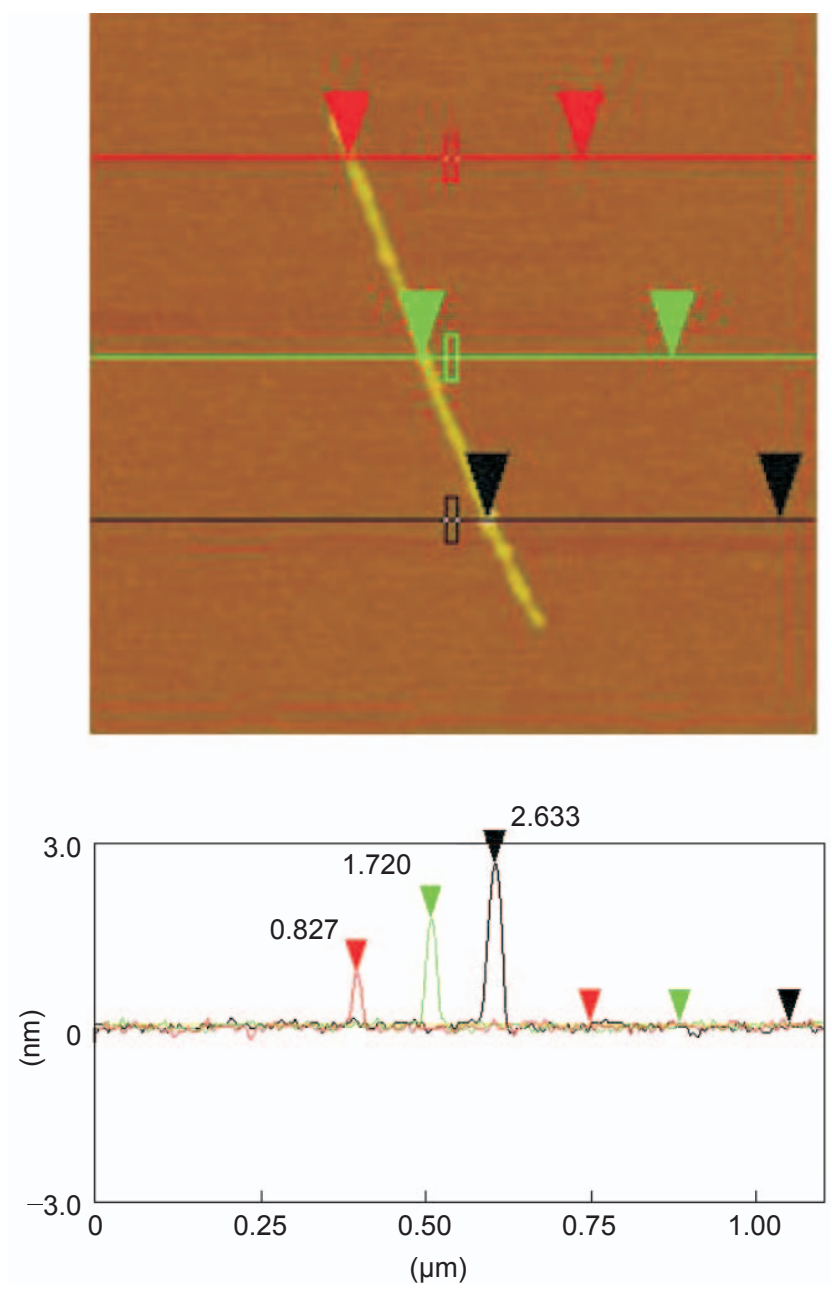

Figure 8 Representative tapping mode AFM image and height profile of OCT-AHA-SWNTS (2)

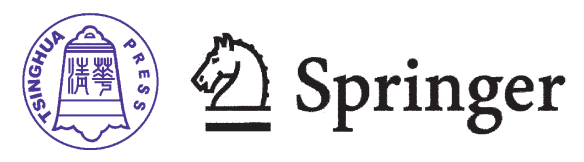




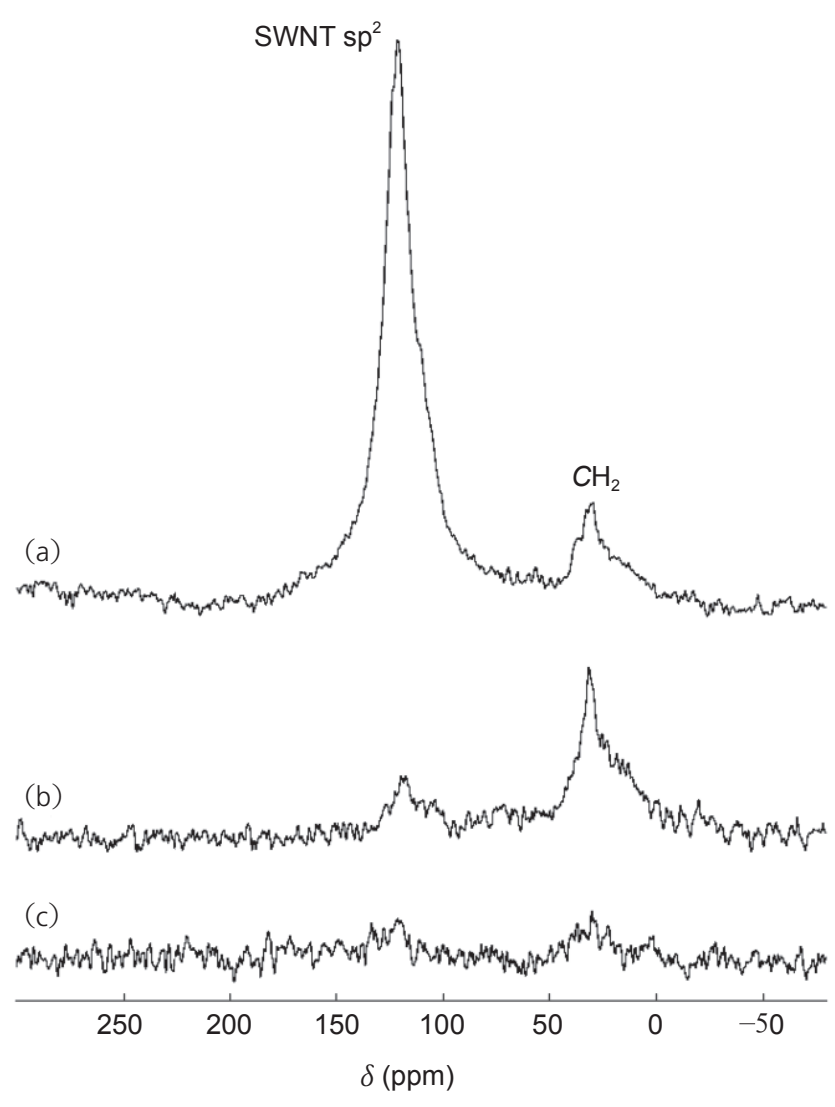

Figure 9 DOD-GLY-SWNT (1), only a partially filled rotor (a) $90^{\circ}{ }^{13} \mathrm{C}$ pulse MAS spectrum (34000 scans), (b) ${ }^{1} \mathrm{H}-{ }^{13} \mathrm{C}$ CPMAS spectrum (51000 scans), and (c) ${ }^{1} \mathrm{H}-{ }^{13} \mathrm{C}$ CPMAS spectrum with a 50- $\mu$ s dephasing interval before FID acquisition (51 000 scans)

carbons (Fig. 9(c)) in a similar manner to that observed for AUDA-SWNT (Fig. 3(c)).

Qualitatively similar results are observed for OCT-AHA-SWNT (2) (Fig. 10), where a large increase in the intensity of the aliphatic peak is also seen in the ${ }^{1} \mathrm{H}^{-}{ }^{13} \mathrm{C}$ CPMAS spectrum (Fig. 10(b)). Just as the precursor AHA-SWNT gave a broad, downfield signal encompassing the range for carboxylic acid groups (Fig. 2(b)), 2 gives a broad, downfield signal encompassing the range for ester carbonyl groups (Fig. 10(b)).

However, of particular significance is the emergence of a weak signal from about $68-81 \mathrm{ppm}$ consistent with sidewall $\mathrm{sp}^{3} \mathrm{C}-\mathrm{N}$ generated upon functionalization. This signal is downfield of where the ester $-\mathrm{O}-\mathrm{CH}_{2}-$ signal would be expected (the most deshielded aliphatic signal from the side chain). For example, $n$-propyl stearate gives an $-\mathrm{OCH}_{2}-$ signal at $\delta=65.8$ relative to TMS in $\mathrm{CDCl}_{3}$ and at $\delta=65.0$ as a

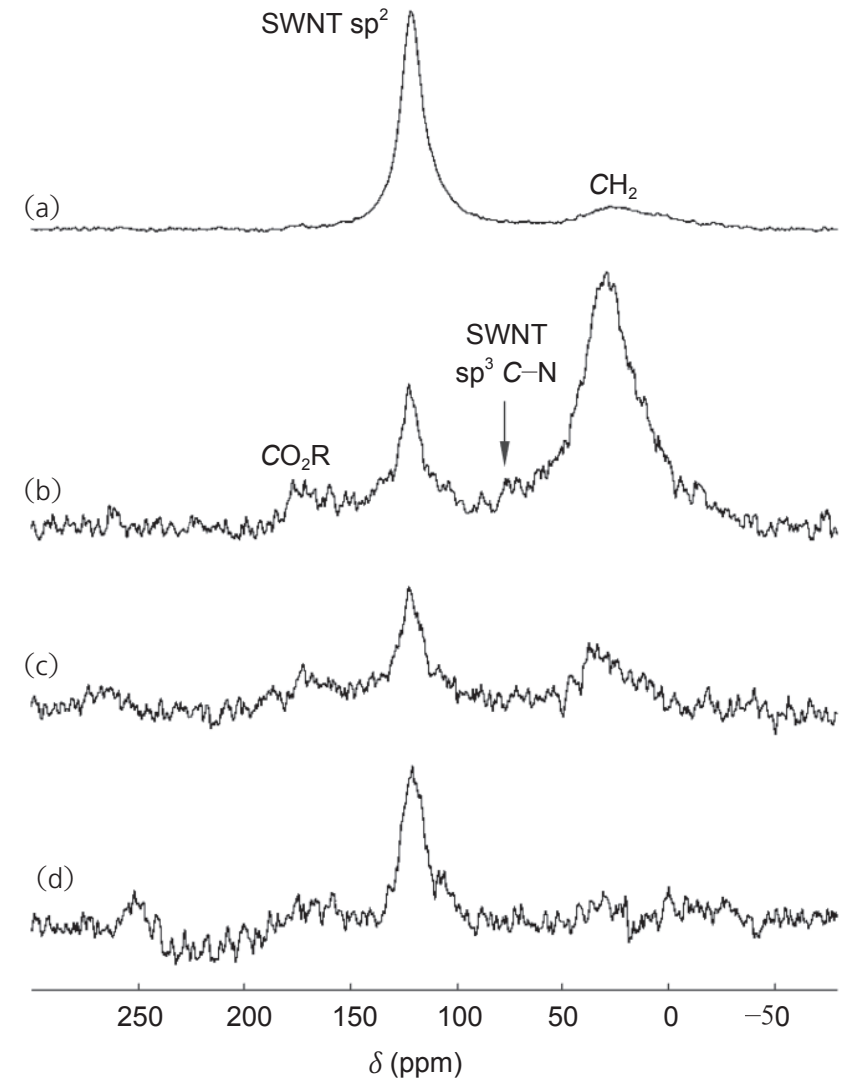

Figure 10 OCT-AHA-SWNT (2): (a) $90{ }^{\circ}{ }^{13} \mathrm{C}$ pulse MAS spectrum (25 600 scans), (b) ${ }^{1} \mathrm{H}-{ }^{13} \mathrm{C}$ CPMAS spectrum (75 000 scans), (c) ${ }^{1} \mathrm{H}$ $-{ }^{13} \mathrm{C}$ CPMAS spectrum with a $50-\mu \mathrm{s}$ dephasing interval before FID acquisition (110 000 scans), and (d) ${ }^{1} \mathrm{H}-{ }^{13} \mathrm{C}$ CPMAS spectrum with an 80- $\mu$ s dephasing interval before FID acquisition (110 000 scans)

solid relative to solid glycine carbonyl defined as $\delta=$ 176.46 (Fig. S-2) [34] and $n$-butyl butanoate gives an $-\mathrm{OCH}_{2}-$ signal at $\delta=64.1$ [35]. A distinctive signal from about 70-80 ppm was not detected in the precursor AHA-SWNT (Fig. 2(b)).

$\mathrm{Ab}$ initio calculations (Fig. 11) of the chemical shift for the sidewall $\mathrm{sp}^{3}$ carbon atoms on an eightycarbon fragment of the 5,5 (armchair) SWNT with substitution of an $\mathrm{N}$-methyl amine $\left(-\mathrm{NH}-\mathrm{CH}_{3}\right)$ (e.g., Fig. 12) suggest the closest model for the observed spectra is 1,2- (as opposed to 1,4-) substitution of at least four amines. The calculated shifts for four adjacent 1,2- substituents are $\delta=67$ and 64 ppm. Given that this is for a limited substitution and on a single chirality SWNT, this result is in good agreement with experimental observation of a broad feature at $68-81 \mathrm{ppm}$. The closest model compounds for the sidewall $\mathrm{sp}^{3} \mathrm{C}-\mathrm{N}$ generated upon functionalization of an SWNT may be a 


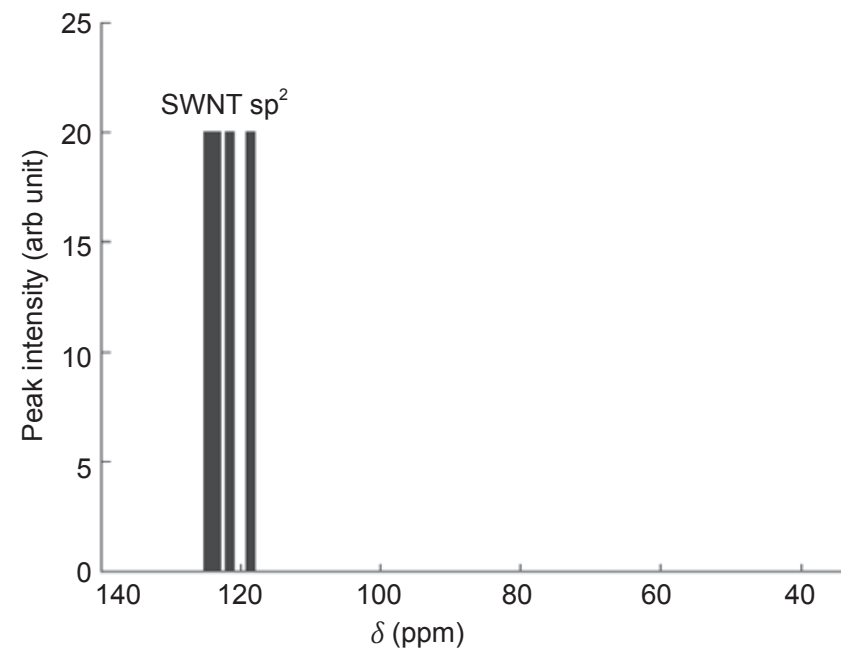

(a)

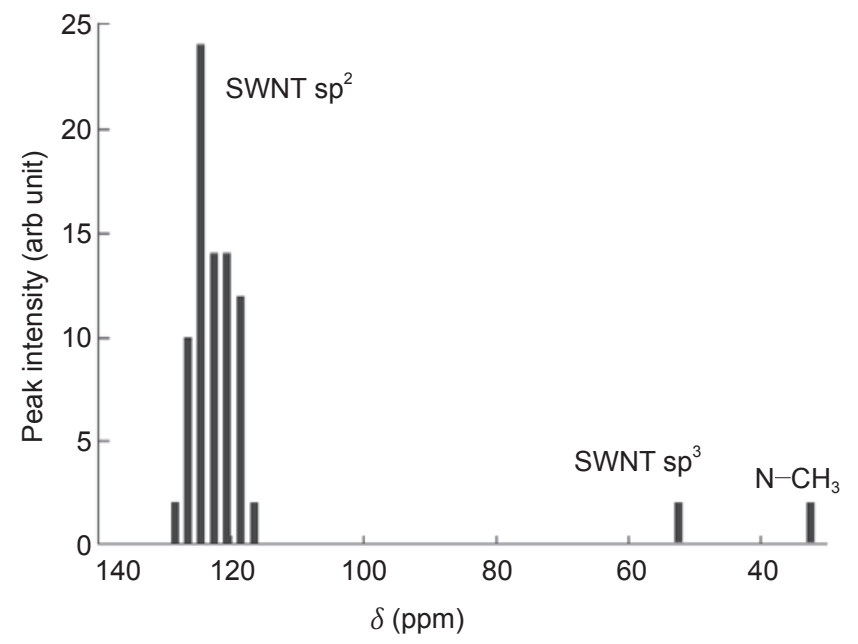

(c)

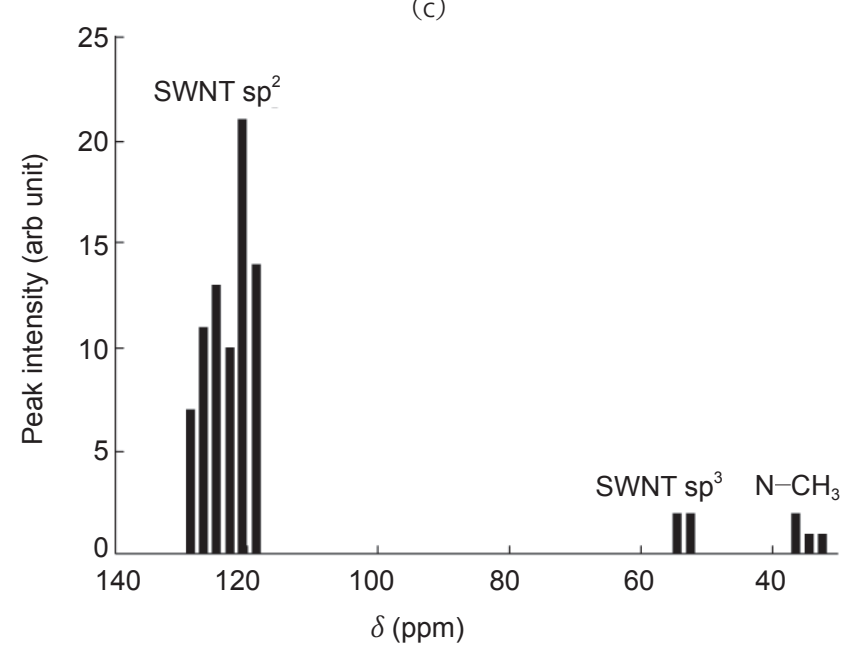

(e)

Figure 11 Calculated ${ }^{13} \mathrm{C}$ NMR shifts for (a) $\mathrm{C}_{80} \mathrm{H}_{20}$ fragment of the 5,5 (armchair) conformation, and as a result of (b) 1,2-addition by two $\mathrm{N}$-methyl amino $\left(-\mathrm{NH}^{-} \mathrm{CH}_{3}\right)$ groups, (c) 1,4-addition by two $\mathrm{N}$-methyl amino $\left(-\mathrm{NH}^{-} \mathrm{CH}_{3}\right)$ groups, (d) 1,2-addition by four $\mathrm{N}$-methyl amino $\left(-\mathrm{NH}^{-} \mathrm{CH}_{3}\right)$ groups, and (e) 1,4-addition by four $\mathrm{N}$-methyl amino $\left(-\mathrm{NH}^{-} \mathrm{CH}_{3}\right)$ groups

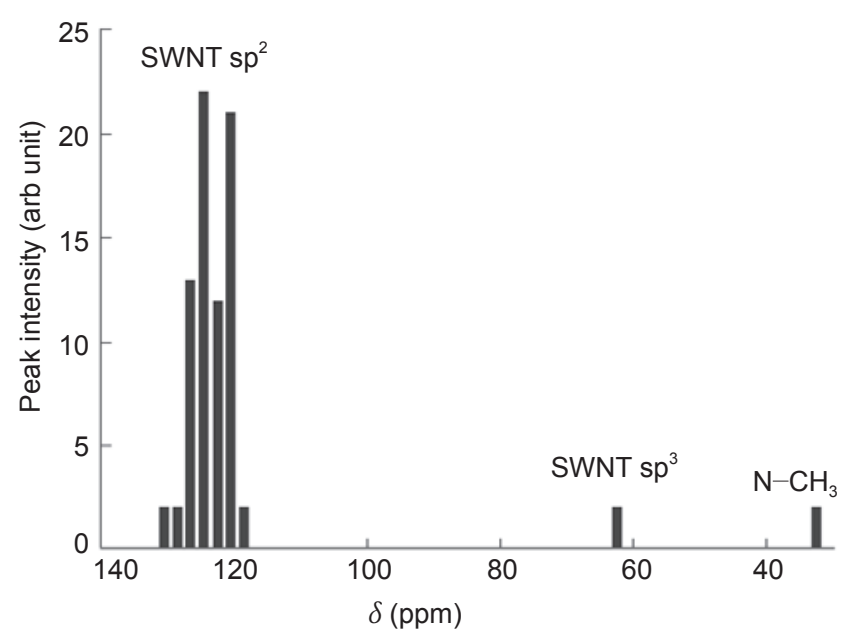

(b)

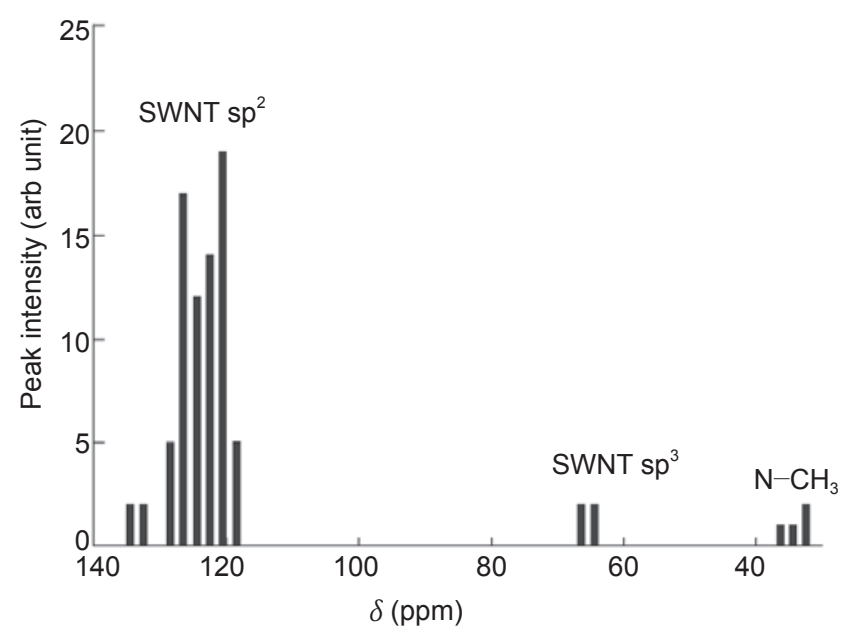

(d)

fullerene derivatized with amines (ideally, primary amines). Numerous amine derivatives of $C_{60}$ [36-50] including derivatives with primary amines [36-49], give fullerene $\mathrm{sp}^{3} \mathrm{C}-\mathrm{N}$ signals with chemical shifts that strongly support the SWNT sidewall $\mathrm{sp}^{3} \mathrm{C}-\mathrm{N}$ assignment for 2 . The quaternary aliphatic carbon of $\left(\mathrm{C}_{6} \mathrm{H}_{5}\right)_{3} \mathrm{C}-\mathrm{NHCH}_{2} \mathrm{CO}_{2} \mathrm{H}$ gives a signal at $\delta=71.6$ relative to TMS in acetone- $d_{6}$.

There have been relatively few theoretical studies on ${ }^{13} \mathrm{C}$ NMR of SWNTs. One of the studies used Hartree-Fork (HF) theory primarily to minimize the computational cost of the calculations [51]. And the results show that the relatively low levels of theory (such as HF/3-21G) provide relatively accurate chemical shifts $(<7$ ppm) compared with more accurate correlated methods. This is presumably because of the error cancellation between the 
shielding constant of the probe and the reference [52]. In addition, our previous studies on ${ }^{13} \mathrm{C}$ NMR calculations of fluorinated SWNTs with the same level of theory show good agreement with experimental results [12].

The dipolar dephasing spectrum of OCTAHA-SWNT (2) is noteworthy for the amount of methylene carbon signal intensity remaining after a 50- $\mu$ s dephasing interval (Fig. 10(c)). None was detected with the precursor AHA-SWNT (Fig. 2(c)). Esterification resulted in significantly longer side chains that appear to be better at separating the nanotubes and creating more space in which the chains can flop around. With an 80- $\mu$ s dephasing interval, the methylene carbon signal has essentially completely decayed (Fig. 10(d)). With an esterification yield for 2 twice that for $\mathbf{1}(70 \%$ vs 35\%), 2 has a higher proportion of the long side chains. Thus, the nanotubes should be better separated in $\mathbf{2}$, consistent with the apparently greater mobility of the side chains in 2.

The direct $90^{\circ}$ pulse ${ }^{13} \mathrm{C}$ MAS NMR spectra of PRO-AUDA-SWNT (3) (Fig. 13(a)) and OCT-AHASWNT (2) (Fig. 10(a)) are qualitatively similar, although the aliphatic and carbonyl signals are more apparent with the former. As with 2, the ${ }^{1} \mathrm{H}-{ }^{13} \mathrm{C}$

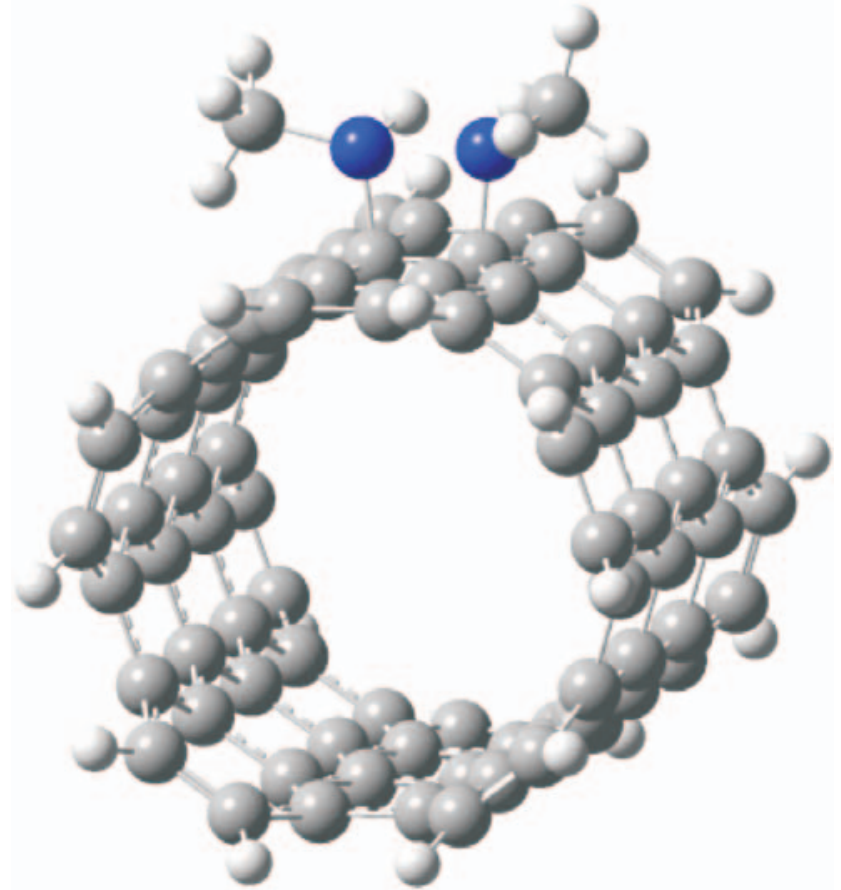

Figure 12 Calculated structure of 5,5 SWNT $\mathrm{C}_{80} \mathrm{H}_{20}$ fragment with two $\mathrm{N}$-methyl amino $\left(-\mathrm{NH}^{-} \mathrm{CH}_{3}\right)$ groups (1,2-addition)
CPMAS spectrum of 3 shows both the ester carbonyl group (167-180 ppm, Fig. 13(b)) and the sidewall $\mathrm{sp}^{3}$ C-N site (69-79 ppm, Fig. 13(b)), with the latter signal clearly evident after 51000 scans. In contrast, the sidewall $\mathrm{sp}^{3} \mathrm{C}-\mathrm{N}$ site had not been clearly detected in the corresponding spectrum of the precursor AUDA-SWNT after 15000 scans (Fig. 3(b)). However, obtaining a CPMAS spectrum of unreacted AUDASWNT with a higher S/N ratio revealed (Fig. 14, 82000 scans) a weak, broad signal centered at about $73 \mathrm{ppm}$, consistent with the sidewall $\mathrm{sp}^{3} \mathrm{C}-\mathrm{N}$ site. In contrast, this signal could not be clearly detected in either the standard CPMAS or dipolar dephasing spectra of DOD-GLY-SWNT (1) or GLY-SWNT, even though the $\mathrm{C}_{\mathrm{SWNT}}$ :substituent ratio is similar for GLY-SWNT, AHA-SWNT, and AUDA-SWNT. The
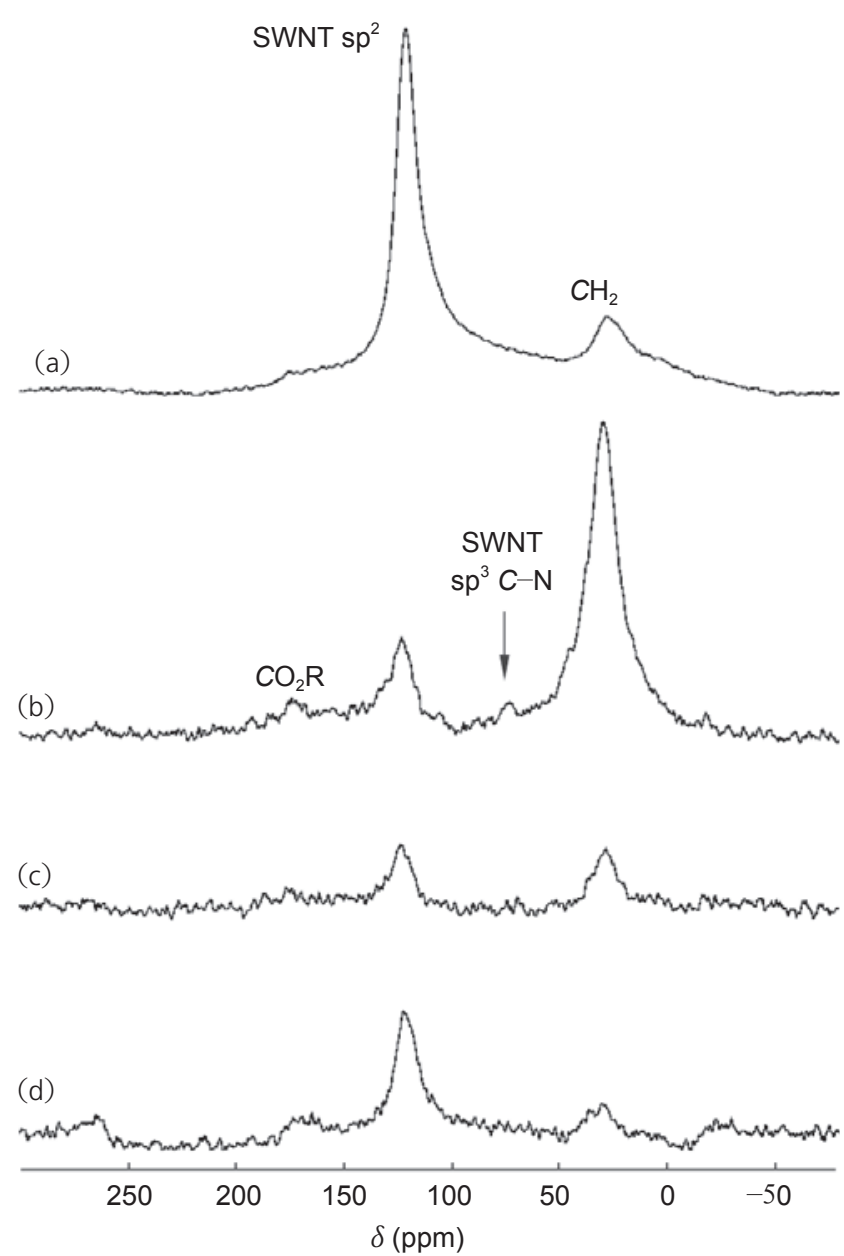

Figure 13 PRO-AUDA-SWNT (3): (a) $90{ }^{\circ 13} \mathrm{C}$ pulse MAS spectrum (33000 scans), (b) ${ }^{1} \mathrm{H}-{ }^{13} \mathrm{C}$ CPMAS spectrum (51 000 scans), (c) ${ }^{1} \mathrm{H}-{ }^{13} \mathrm{C}$ CPMAS spectrum with a $50-\mu$ s dephasing interval before FID acquisition (51000 scans), and (d) ${ }^{1} \mathrm{H}-{ }^{13} \mathrm{C}$ CPMAS spectrum with an $80-\mu$ s dephasing interval before FID acquisition (51000 scans) 
difficulty in CPMAS NMR detection of the sidewall $\mathrm{sp}^{3} \mathrm{C}-\mathrm{N}$ site in the amino acid-functionalized SWNTs is similar to the situation encountered with $\mathrm{C}_{60}$ bound to a polystyrene derivative through its pendant primary amines: for this polymer-bound $\mathrm{C}_{60}$, the analogous $\mathrm{C}_{60} \mathrm{sp}^{3} \mathrm{C}-\mathrm{N}$ site was not detected by CPMAS NMR [53].

As was the case with OCT-AHA-SWNT (2), the dipolar dephasing spectrum of PRO-AUDA-SWNT (3) is noteworthy for the amount of methylene carbon signal intensity remaining after a $50-\mu$ s dephasing interval (Fig. 13(c)). Indeed, the methylene carbon signal intensity is less attenuated than in the dipolar dephasing spectrum of the precursor AUDA-SWNT (Fig. 3(c)), thus suggesting even more mobility in the PRO-AUDA side chain than in the AUDA side chain. The combination of chain lengthening and higher esterification yields ( $80 \%$ for 3 ) results in more separation of the nanotubes, in light of the dipolar dephasing spectra indicating that side chain mobility increases in the order AHA-SWNT $<$ AUDA-SWNT $<$ OCT-AHA-SWNT < PRO-AUDA-SWNT. Even with an $80-\mu$ s dephasing interval, some aliphatic intensity clearly remains for PRO-AUDA-SWNT (Fig. 13(d)). A comparison of the standard CP spectra and spectra obtained with dephasing intervals of $50 \mu \mathrm{s}$ and $80 \mu \mathrm{s}$ for 2 and 3 clearly shows the slower decay of the aliphatic signal for 3 (Figs. 10 and 13). In each sample, the aliphatic signal decays much more rapidly than

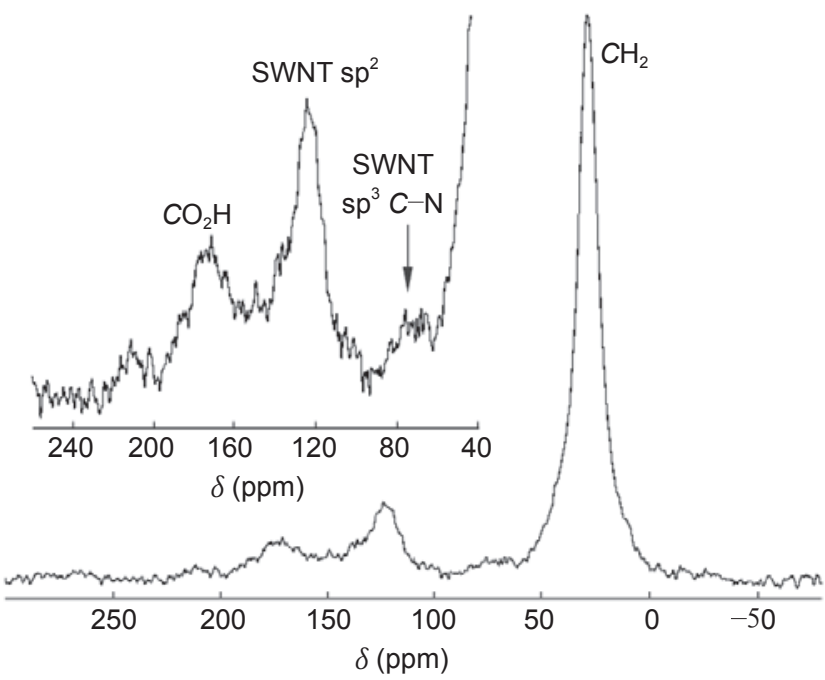

Figure 14 AUDA-SWNT (15 mg): ${ }^{1} \mathrm{H}-{ }^{13} \mathrm{C}$ CPMAS spectrum (82 000 scans). Inset shows an expanded plot of the region from 260 to 40 ppm the nanotube $\mathrm{sp}^{2}$ and carbonyl signals, as expected.

Stearic acid $\left[\mathrm{CH}_{3}\left(\mathrm{CH}_{2}\right)_{16} \mathrm{CO}_{2} \mathrm{H}\right]$ and $n$-propyl stearate $\left[\mathrm{CH}_{3}\left(\mathrm{CH}_{2}\right)_{16} \mathrm{C}(\mathrm{O}) \mathrm{OCH}_{2} \mathrm{CH}_{2} \mathrm{CH}_{3}\right]$ serve as useful model compounds for demonstrating the effect of increased motional freedom in the solid state on the rate of methylene carbon signal decay in the dipolar dephasing experiment. Discussion and relevant spectra appear in the Supporting Information.

In order to demonstrate that the slowly decaying aliphatic signal in the dipolar dephasing spectra for 1-3 results from $\mathrm{CH}_{2}$ groups rather than from an unusually deshielded terminal $\mathrm{CH}_{3}$ group (which would be expected to decay much more slowly [27]), we prepared the ester of AUDA-SWNT with 1,3-propanediol to yield PPD-AUDA-SWNT (4). As may be seen in Fig. 15, replacing the $\mathrm{CH}_{3}$ group with a $\mathrm{CH}_{2} \mathrm{OH}$ group does not significantly alter the various spectra as compared to those from 3 . In particular,
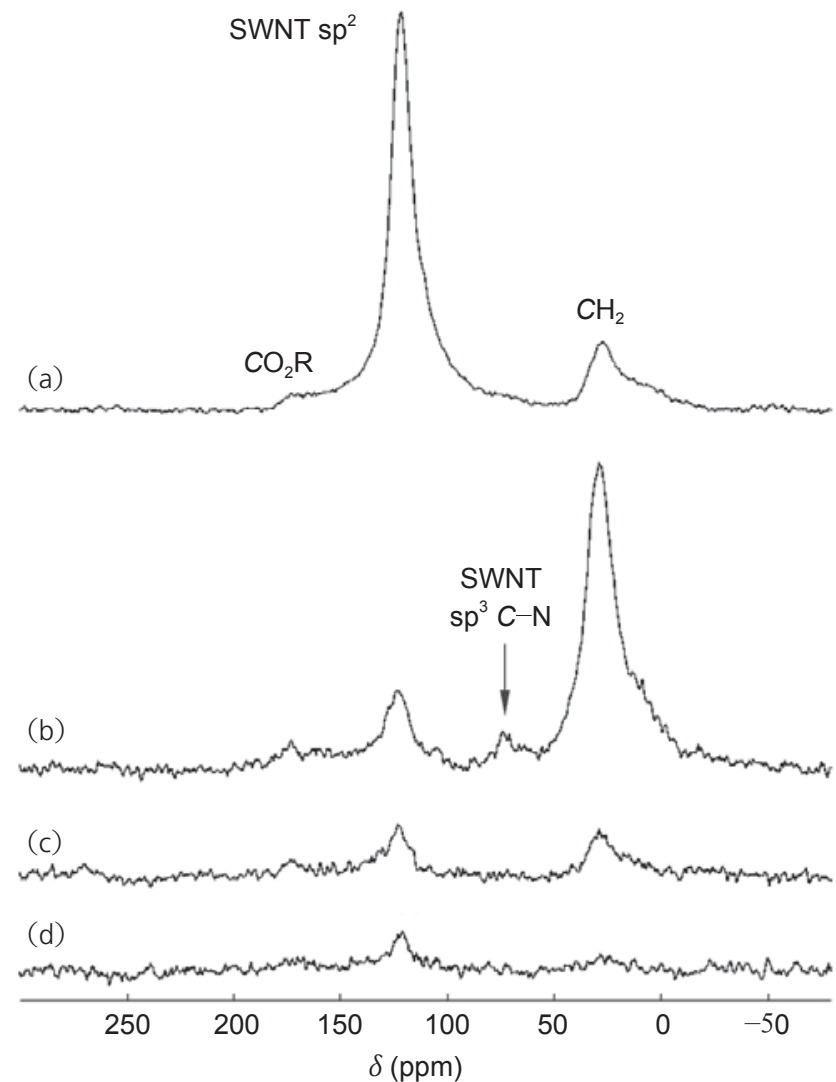

Figure 15 PPD-AUDA-SWNT (4): (a) $90^{\circ}{ }^{13} \mathrm{C}$ pulse MAS spectrum (15 400 scans), (b) ${ }^{1} \mathrm{H}-{ }^{13} \mathrm{C}$ CPMAS spectrum (34 200 scans), (c) ${ }^{1} \mathrm{H}-$ ${ }^{13} \mathrm{C}$ CPMAS spectrum with a $50-\mu$ s dephasing interval before FID acquisition (34200 scans), and (d) ${ }^{1} \mathrm{H}-{ }^{13} \mathrm{C}$ CPMAS spectrum with an $80-\mu$ dephasing interval before FID acquisition (34 200 scans) 
a comparable amount of aliphatic signal intensity remains with a 50- $\mu$ s dephasing interval (Fig. 15(c)). In addition, the propyl methyl carbon chemical shift of $n$-propyl stearate ( $\delta=10$ ppm, Fig. S-2(a)) is clearly upfield of the aliphatic signal from 3 (Fig. 13(c) and (d)). Thus, the slowly decaying aliphatic signals in the dipolar dephasing spectra of 3 must be from methylene carbons.

In this context, it is worth noting another report of a solid that has methylene carbons exhibiting unusually slow dipolar dephasing rates because of unusually large molecular motion. Such motion is found in the non-crystalline component of a meltquenched polyethylene, a complex solid consisting of a crystalline component, a non-crystalline component, and a third component [54]. Furthermore, the noncrystalline component itself clearly has two different types of structures with dipolar dephasing rates differing by an order of magnitude (a typical fast rate and the atypical slow rate). The authors [54] indicated that the transition rate between trans and gauche conformers in this component is very high and that the dephasing time is a measure of molecular motion.

Similarly, dipolar dephasing experiments on some low-rank coals have provided evidence for segmental motion thought to arise from methylene groups associated with hydroaromatic and/or polymethylene structural units [55]. Dipolar dephasing rates differing by up to an order of magnitude were observed for the signal at $30 \mathrm{ppm}$ in the nonmobile and mobile components [55]. A similar study on another coal also provided evidence for segmental motion associated with the moieties giving rise to the signal at $30 \mathrm{ppm}$ [56].

A few small, nearly spherical molecules (frozen norbornadiene [57], 1-bromoadamantane [58], and 1-chloroadamantane [59]) have also been shown to give exceptionally slowly decaying signals for protonbearing carbons in dipolar dephasing experiments because rapid, nearly isotropic rotation greatly reduces the effective ${ }^{13} \mathrm{C}^{-1} \mathrm{H}$ dipole-dipole interaction. The data for the melt-quenched polyethylene [54] and the amino acid-functionalized SWNTs clearly show that this phenomenon, while rare, is not limited to small, nearly spherical molecules.

The variable that appears to show a consistent effect in controlling the relaxation of the aliphatic carbons is chain length. Short chain lengths (e.g., GLYSWNT and AHA-SWNT) should result in relatively tight bundling of functionalized SWNTs in the solid state (Fig. 16(a)). In contrast, functionalized SWNTs with longer chained substituents will be held further apart (Fig. 16(b)). AFM, TEM, and Raman suggest that the amino acid (and hence ester) moieties are distributed along the sidewall, we propose that void spaces are present between the SWNTs in the solid state. Thus, the freedom of movement of the chain will be greater for longer functional groups, and the relaxation of the aliphatic carbon atoms would approach that of the "liquid" or "molten" state [60], resulting in a more slowly decaying aliphatic signal in the dipolar dephasing experiment. Such a trend is indeed observed.

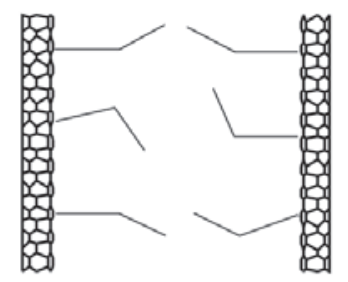

(a)
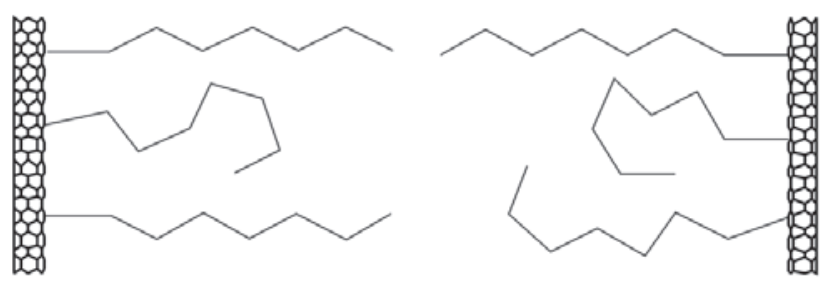

(b)

Figure 16 Schematic representations of the SWNT $\cdots$ SWNT interbundle distance and side chain mobility as a function of side chain length

\section{Conclusions}

Given that SWNTs are often discussed as "molecules" it is strange that NMR has not been used more to characterize functionalized SWNTs. NMR is probably the most powerful and readily applied characterization method for organic and organometallic compoundssolid state NMR has been used extensively for inorganic solids [61-73] but NMR's use in nano is limited. In particular, the observation of $\mathrm{sp}^{3}$ carbon would go a long way to confirm the sidewall functionalization of SWNTs. 
We report that the MAS ${ }^{13} \mathrm{C}$ NMR spectrum of sidewall functionalized SWNTs is highly dependent on the length of the substituents chain. Initially using a long carboxylic acid or increasing the substituent length through subsequent chemical reaction (without additional substitution of the SWNT) allows for the confirmation of the covalent nature of the substituent on the SWNT. We propose that the use of such an approach will be useful in the further characterization of functionalized SWNTs.

The increase in the side chain length has the additional result of creating more space in which the chains can flop around allowing for somewhat more motional freedom of the side chain than expected at ambient temperature in the solid state. This is observed via the unusual retention of methylene carbon signal intensity in the dipolar dephasing spectrum. We propose that this observation could be used as a method of studying the solid-state interactions between functionalized SWNTs or between functionalized SWNTs and matrix materials.

\section{Acknowledgements}

Financial support for this work is provided by the Robert A. Welch Foundation, and the National Science Foundation through the Center for Biological and Environmental Nanotechnology (EEC-0647452).

Supplementary Material Available: TGA and IR spectra of functionalized SWNTs. TEM image of OCTAHA-SWNTs (2). NMR spectra of stearic acid and $n$-propyl stearate. This material is available free of charge via the Internet at http: / www.springerlink.com

\section{References}

[1] Lichtenberger, D. L.; Hogan, R. H.; Healy, M. D.; Barron, A. R. Electronic structure and bonding in four-coordinate organometallic complexes of aluminum. Valence photoelectron spectra of $\mathrm{BHT}-\mathrm{H}, \mathrm{Me}_{3} \mathrm{Al}\left(\mathrm{PMe}_{3}\right)$, and $\mathrm{Me}_{2}(\mathrm{BHT}) \mathrm{Al}\left(\mathrm{PMe}_{3}\right)$. J. Am. Chem. Soc. 1990, 112, 33693374.

[2] Lichtenberger, D. L.; Hogan, R. H.; Healy, M. D.; Barron, A. R. Electronic structure and bonding in fourcoordinate organometallic complexes of aluminum.
Valence photoelectron spectra of $\mathrm{Me}_{3} \mathrm{Al}$ (pyridine) and $\mathrm{Me}_{2}(\mathrm{BHT}) \mathrm{Al}$ (pyridine) (BHT=2,6-di-tert-butyl-4methylphenoxide). Organometallics. 1991, 10, 609614.

[3] Healy, M. D.; Ziller, J. W.; Barron, A. R. Bonding in fourcoordinate aluminum aryloxide compounds. J. Am. Chem. Soc. 1990, 112, 2949-2954.

[4] Barron, A. R.; Dobbs, K. D.; Francl, M. M. Theoretical investigation of aluminum-oxygen $\pi$-bonding in 3 - and 4-coordinate aluminum alkoxides. J. Am. Chem. Soc. 1991, 113, 39-43.

[5] Francis, J. A.; McMahon, C. N.; Bott, S. G.; Barron, A. R. Steric effects in aluminum compounds containing monoanionic potentially bidentate ligands: Toward a quantitative measure of steric bulk. Organometallics 1999, 18, 4399-4416.

[6] Apblett, A. W.; Warren, A. C.; Barron, A. R. Synthesis and characterization of triethylsiloxy-substituted alumoxanes: Their structural relationship to the minerals boehmite and diaspore. Chem. Mater. 1992, 4, 167-182.

[7] Bethley, C. E.; Aitken, C. L.; Koide, Y.; Harlan, C. J.; Bott, S. G.; Barron, A. R. Structural characterization of dialkylaluminum carboxylates: Models for carboxylate alumoxanes. Organometallics 1997, 16, 329-341.

[8] Koide, Y.; Barron, A. R. [ $\left[\mathrm{Al}_{5}\left({ }^{\mathrm{t}} \mathrm{Bu}\right)_{5}\left(\mu_{3}-\mathrm{O}\right)_{2}\left(\mu_{3}-\mathrm{OH}\right)_{2}(\mu-\mathrm{OH})_{2}(\mu-\right.$ $\mathrm{O}_{2}(\mathrm{CPh})_{2}$ ]: A model for the interaction of carboxylic acids with boehmite. Organometallics 1995, 14, 4026-4029.

[9] Zeng, L.; Zhang, L.; Barron, A. R. Tailoring aqueous solubility of functionalized single-wall carbon nanotubes over a wide $\mathrm{pH}$ range through substituent chain length. Nano Lett. 2005, 5, 2001-2004.

[10] Zhang, L.; Zeng, L.; Barron, A. R.; Monteiro-Riviere, N. A. Biological interactions of functionalized single-wall carbon nanotubes in human epidermal keratinocytes. Int. J. Toxicol. 2007, 26, 103-113.

[11] Dillon, E. P.; Crouse, C. A.; Barron, A. R. Synthesis, characterization, and carbon dioxide adsorption of covalently attached polyethyleneimine-functionalized single-wall carbon nanotubes. ACS Nano 2008, 2, 156164.

[12] Alemany, L. B.; Zeng, L.; Zhang, L.; Edwards, C. L.; Barron, A. R. Solid-state NMR analysis of fluorinated single-walled carbon nanotubes: Assessing the extent of fluorination. Chem. Mater. 2007, 19, 735-744.

[13] Zhang, L.; Yang, J.; Edwards, C. L.; Alemany, L. B.; Khabashesku, V. N.; Barron, A. R. Diels-Alder addition 
to fluorinated single walled carbon nanotubes. Chem. Commun. 2005, 26, 3265-3267.

[14] Zurek, E.; Autschbach, J. Density functional calculations of the ${ }^{13} \mathrm{C}$ NMR chemical shifts in $(9,0)$ single-walled carbon nanotubes. J. Am. Chem. Soc. 2004, 126, 1307913088.

[15] Mickelson, E. T.; Chiang, I. W.; Zimmerman, J. L.; Boul, P. J.; Lozano, J.; Liu, J.; Smalley, R. E.; Hauge, R. H.; Margrave, J. L. Solvation of fluorinated single-wall carbon nanotubes in alcohol solvents. J. Phys. Chem. $B$ 1999, 103, 4318-4322.

[16] Kitaygorodskiy, A.; Wang, W.; Xie, S.-Y.; Lin, Y.; Fernando, K. A. S.; Wang, X.; Qu, L.; Chen, B.; Sun, Y.-P. NMR detection of single-walled carbon nanotubes in solution. J. Am. Chem. Soc. 2005, 127, 7517-7520.

[17] Cahill, L. S.; Yao, Z.; Adronov, A.; Penner, J.; Moonoosawmy, K. R.; Kruse, P.; Goward, G. R. Polymerfunctionalized carbon nanotubes investigated by solid-state nuclear magnetic resonance and scanning tunneling microscopy. J. Phys. Chem. B 2004, 108, 11412-11418.

[18] Bac, C. G.; Bernier, P.; Latil, S.; Jourdain, V.; Rubio, A.; Jhang, S. H.; Lee, S. W.; Park, Y. W.; Holzinger, M.; Hirsch, A. ${ }^{13} \mathrm{C}$ NMR investigation of carbon nanotubes and derivatives. Curr. Appl. Phys. 2001, 1, 149-155.

[19] Peng, H.; Alemany, L. B.; Margrave, J. L.; Khabashesku, V. N. Sidewall carboxylic acid functionalization of singlewalled carbon nanotubes. J. Am. Chem. Soc. 2003, 125, 15174-15182.

[20] Liang, F.; Alemany, L. B.; Beach, J. M.; Billups, W. E. Structure analyses of dodecylated single-walled carbon nanotubes. J. Am. Chem. Soc. 2005, 127, 1394113948.

[21] Chiang, I. W.; Brinson, B. E.; Huang, A. Y.; Willis, P. A.; Bronikowski, M. J.; Margrave, J. L.; Smalley, R. E.; Hauge, R. H. Purification and characterization of single-wall carbon nanotubes (SWNTs) obtained from the gas-phase decomposition of CO (HiPco process). J. Phys. Chem. B 2001, 105, 8297-8301.

[22] Mickelson, E. T.; Huffman, C. B.; Rinzler, A. G.; Smalley, R. E.; Hauge, R. H.; Margrave, J. L. Fluorination of singlewall carbon nanotubes. Chem. Phys. Lett. 1998, 296, 188-194.

[23] Frisch, M. J.; Trucks, G. W.; Schlegel, H. B.; Scuseria, G. E.; Robb, M. A.; Cheeseman, J. R.; Montgomery, J. A., Jr.; Vreven, T.; Kudin, K. N.; Burant, J. C.; Yazyev, O., et al.
Gaussian 03, Revision 02; Gaussian Inc.: Wallingford, CT, 2004.

[24] Ashcroft, J. M.; Hartman, K. B.; Mackeyev, Y.; Hofmann, C.; Pheasant, S.; Alemany, L. B.; Wilson, L. J. Functionalization of individual ultra-short single-walled carbon nanotubes. Nanotechnology 2006, 17, 5033-5037.

[25] Bielecki, A.; Burum, D. P. Temperature dependence of ${ }^{207} \mathrm{~Pb}$ MAS spectra of solid lead nitrate. An accurate, sensitive thermometer for variable-temperature MAS. J. Magn. Reson. A 1995, 116, 215-210.

[26] Engtrakul, C.; Davis, M. F.; Gennett, T.; Dillon, A. C.; Jones, K. M.; Heben, M. J. Protonation of carbon singlewalled nanotubes studied using ${ }^{13} \mathrm{C}$ and ${ }^{1} \mathrm{H}-{ }^{13} \mathrm{C}$ cross polarization nuclear magnetic resonance and raman spectroscopies. J. Am. Chem. Soc. 2005, 127, 1754817555.

[27]Opella, S. J.; Frey, M. H.; Cross, T. A. Detection of individual carbon resonances in solid proteins. J. Am. Chem. Soc. 1979, 101, 5856-5857.

[28] Alemany, L. B.; Grant, D. M.; Alger, T. D.; Pugmire, R. J. Cross polarization and magic angle sample spinning NMR spectra of model organic compounds. 3. Effect of the carbon-13-proton dipolar interaction on cross polarization and carbon-proton dephasing. J. Am. Chem. Soc. 1983, 105, 6697-6704.

[29] Groombridge, C. J.; Harris, R. K.; Packer, K. J.; Say, B. J.; Tanner, S. F. High-resoldution carbon-13 NMR spectra of solid nitrogen-containing compound. J. Chem. Soc., Chem. Commun. 1980, 4, 174-175.

[30] Frey, M. H.; Opella, S. J. High-resolution features of the carbon-13 NMR spectra of solid amino acids and peptides. J. Chem. Soc., Chem. Commun. 1980, 11, 474-475.

[31] Hexem, J. G.; Frey, M. H.; Opella, S. J. Influence of nitrogen-14 on carbon-13 NMR spectra of solids. J. Am. Chem. Soc. 1981, 103, 224-226.

[32] Naito, A.; Ganapathy, S.; McDowell, C. A. High resolution solid state carbon-13 NMR spectra of carbons bonded to nitrogen in a sample spinning at the magic angle. J. Chem. Phys. 1981, 74, 5393-5397.

[33] Azamian, B. R.; Coleman, K. S.; Davis, J. J.; Hanson, N.; Green, M. L. H. Directly observed covalent coupling of quantum dots to single-wall carbon nanotubes. Chem. Commun. 2002, 4, 366-367.

[34] Hayashi, S.; Hayamizu, K. Chemical shift standards in highresolution solid-state NMR. 1. Carbon-13, silicon-29, and proton nuclei. Bull. Chem. Soc. Jpn. 1991, 64, 685-687. 
[35] Alemany, L. B. Ph.D. Dissertation, Investigations on the Reactivity and Organic Structure of Illinois No. 6 Coal, University of Chicago, USA, 1980.

[36] Kampe, K.-D.; Egger, N.; Vogel, M. Diamino and tetraamino derivatives of buckminsterfullerene $C_{60}$. Angew. Chem. Int. Ed. 1993, 32, 1174-1176.

[37] Kampe, K.-D., Egger, N. Reactions of diamines with fullerene $C_{60}$. Liebigs Annalen 1995, 1, 115-124.

[38] Schick, G.; Kampe, K.-D.; Hirsch, A. Reaction of [60]fullerene with morpholine and piperidine: Preferred 1,4-additions and fullerene dimer formation. J. Chem. Soc., Chem. Commun. 1995, 19, 2023-2024.

[39] Lamparth, I.; Maichle-Mössmer, C.; Hirsch, A. Reversible template-directed activation of equatorial double bonds of the fullerene framework: Regioselective direct synthesis, crystal structure, and aromatic properties of Th- $\mathrm{C}_{66}(\text { COOEt })_{12}$. Angew. Chem. Int. Ed. 1995, 34, 16071609.

[40] Troshina, O. A.; Troshin, P. A.; Peregudov, A. S.; Lyubovskaya, R. N. Unexpected interconversion reaction of 1,4-diaminofullerenes. Org. Biomol. Chem. 2006, 4, 1647-1649.

[41] Troshina, O. A.; Troshin, P. A.; Peregudov, A. S.; Kozlovski, V. I.; Lyubovskaya, R. N. Photoaddition of N-substituted piperazines to $C_{60}$ : An efficient approach to the synthesis of water-soluble fullerene derivatives. Chem-Eur. J. 2006, 12, 5569-5577.

[42] Troshina, O. A.; Troshin, P. A.; Peregudov, A. S.; Balabaeva, E. M.; Kozlovski, V. I.; Lyubovskaya, R. N. Reactions of chlorofullerene $\mathrm{C}_{60} \mathrm{C}_{16}$ with $\mathrm{N}$-substituted piperazines. Tetrahedron 2006, 62, 10147-10151.

[43] Isobe, H.; Ohbayashi, A.; Sawamura, M.; Nakamura, E. A cage with fullerene end caps. J. Am. Chem. Soc. 2000, 122, 2669-2670.

[44] Isobe, H.; Tomita, N.; Nakamura, E. One-step multiple addition of amine to [60]fullerene. synthesis of tetra(amino)fullerene epoxide under photochemical aerobic conditions. Org. Lett. 2000, 2, 3663-3665.

[45] Isobe, H.; Tanaka, T.; Nakanishi, W.; Lemiègre, L.; Nakamura, E. Regioselective oxygenative tetraamination of [60]fullerene. fullerene-mediated reduction of molecular oxygen by amine via ground state single electron transfer in dimethyl sulfoxide. J. Org. Chem. 2005, 70, 4826-4832.

[46] Butts, C. P.; Jazdzyk, M. The preparation and structures of non-hydrocarbon functionalized fullerene-diamine adducts. Chem. Commun. 2003, 13, 1530-1531.

[47] Butts, C. P.; Jazdzyk, M. D. S. Piperazine additions to $\mathrm{C}_{60}$-A facile approach to fullerene substitution. Org. Biomol. Chem. 2005, 3, 1209-1216.

[48] Evlampieva, N. P.; Yakimanskii, A. V.; Dobrodumov, A. V.; Nazarova, O. V.; Pashkov, Y. B.; Panarin, E. F.; Ryumtsev, E. I. Synthesis and polar and electrooptical properties of a butylamine derivative of fullerene $\mathrm{C}_{60}$. Russ. J. Gen. Chem. 2005, 75, 751-758.

[49] Hu, X.; Jiang, Z.; Jia, Z.; Huang, S.; Yang, X.; Li, Y.; Gan, L.; Zhang, S.; Zhu, D. Amination of [60]fullerene by ammonia and by primary and secondary aliphatic amines-preparation of amino[60]fullerene peroxides. Chem-Eur. J. 2007, 13, 1129-1141.

[50] Meza-Laguna, V.; Basiuk, E. V.; Alvarez-Zauco, E.; AcostaNajarro, D.; Basiuk, V. A. Cross-linking of $\mathrm{C}_{60}$ films with 1,8-diaminooctane and further decoration with silver nanoparticles. J. Nanosci. Nanotechnol. 2007, 7, 35633571.

[51] Besley, N. A.; Titman, J. J.; Wright, M. D. Theoretical study of the ${ }^{13} \mathrm{C}$ NMR spectroscopy of single-walled carbon nanotubes. J. Am. Chem. Soc. 2005, 127, 17948-17953.

[52] Zurek, E.; Pickard, C. J.; Walczak, B.; Autschbach, J. Density functional study of the ${ }^{13} \mathrm{C}$ NMR chemical shifts in small-to-medium-diameter infinite single-walled carbon nanotubes. J. Phys. Chem. A 2006, 110, 1199512004.

[53] Geckeler, K. E.; Hirsch, A. Polymer-bound $C_{60}$. J. Am. Chem. Soc. 1993, 115, 3850-3851.

[54] Chen. Q.; Yamada, T.; Kurosu, H.; Ando, I.; Shionon, T.; Doi, Y. Dynamic study of the noncrystalline phase of carbon-13-labeled polyethylene by variable-temperature carbon-13 CP/MAS NMR spectroscopy. J. Polym. Sci., Part B: Polym. Phys. 1992, 30, 591-601.

[55] Soderquist, A.; Burton, D. J.; Pugmire, R. J.; Beeler, A. J.; Grant, D. M.; Durand, B.; Huk, A. Y. Structural variations and evidence of segmental motion in the aliphatic region in coals observed with dipolar-dephasing NMR. Energy Fuels 1987, 1, 50-55.

[56] Wilson, M. A.; Pugmire, R. J.; Karas, J.; Alemany, L. B.; Woolfenden, W. R.; Grant, D. M.; Given, P. H. Carbon distribution in coals and coal macerals by cross polarization magic angle spinning carbon-13 nuclear magnetic resonance spectrometry. Anal. Chem. 1984, 56, 933-943.

[57] Alla, M.; Lippmaa, E. High resolution broad line carbon- 
13 NMR and relaxation in solid norbornadiene. Chem. Phys. Lett. 1976, 37, 260-264.

[58] Huang, Y.; Gilson, D. F. R.; Butler, I. S.; Morin, F. Study of molecular motions in the orientationally disordered organic solids 1-bromoadamantane and 1-adamantanecarboxylic acid by carbon-13 NMR spin-lattice relaxation and dipolar dephasing time measurements. J. Phys. Chem. 1991, 95, 2151-2156.

[59] Huang, Y.; Paroli, R. M.; Gilson, D. F. R; Butler, I. S. Order-disorder transitions in adamantane derivatives: Vibrational spectroscopic and carbon-13 NMR studies of 1-chloroadamantane. Can. J. Chem. 1993, 71, 18901897.

[60] Aitken, C. L.; Barron, A. R. Crystal structure of $\mathrm{Al}\left({ }^{\mathrm{t}} \mathrm{Bu}\right)_{3}\left(\mathrm{NH}_{2} \mathrm{CH}_{2} \mathrm{CH}_{2} \mathrm{Ph}\right)$ : A molecular "slinky". J. Chem. Crystal. 1996, 26, 297-300.

[61] Alemany, L. B. Critical factors in obtaining meaningful fast MAS NMR spectra of non-integral spin quadrupolar nuclei. A review with particular emphasis on aluminum-27 MAS NMR of catalysts and minerals. Appl. Magn. Reson. 1993, 4, 179-201.

[62] Alemany, L. B.; Steuernagel, S.; Amoureux, J. -P.; Callender, R. L.; Barron, A. R. Very fast MAS and MQMAS NMR studies of the spectroscopically challenging minerals kyanite and andalusite on 400, 500, and 800 $\mathrm{MHz}$ spectrometers. Solid State Nucl. Magn. Reson. 1999, 14, 1-18.

[63] Alemany, L. B.; Callender, R. L.; Barron, A. R.; Steuernagel, S.; luga, D.; Kentgens, A. P. M. Single-pulse MAS, selective Hahn echo MAS, and 3QMAS NMR studies of the mineral zoisite at 400, 500, 600, and $800 \mathrm{MHz}$. Exploring the limits of Al NMR detectability. J. Phys. Chem. B 2000, 104,
11612-11616.

[64] Stebbins, J. F. Dynamics and structure of silicate and oxide melts: Nuclear magnetic resonance studies. Rev. Minera. Geochem. 1995, 32, 191-246.

[65] Nakata, S.; Tanaka, Y.; Asaoka, S.; Nakamura, M. Recent advances in applications of multinuclear solid-state NMR to heterogeneous catalysis and inorganic materials. J. Mol. Struct. 1998, 441, 267-281.

[66] Fitzgerald, J. J.; DePaul, S. M. Solid-state NMR spectroscopy of inorganic materials. ACS Symp. Ser. 1999, 717, 2-133.

[67] Pruski, M.; Amoureux, J. P.; Fernandez, C. Magn. Reson. Colloid Interface Sci: NATO Sci. Ser., I/ 2002, 76, 107113.

[68] Gan, Z. In Encyclopedia of Nuclear Magnetic Resonance; Wiley: Chichester 2002; Vol. 9, pp 132-141.

[69] Frydman L. In Encyclopedia of Nuclear Magnetic Resonance; Wiley: Chichester 2002; Vol. 9, pp 262-274.

[70] Rocha, J.; Morais, C. M.; Fernandez, C. Progress in multiple-quantum magic-angle spinning NMR spectroscopy. Top. Curr. Chem. 2004, 246, 141-194.

[71] Ashbrook, S. E.; Wimperis, S. High-resolution NMR of quadrupolar nuclei in solids: The satellite-transition magic angle spinning (STMAS) experiment. Prog. Nucl. Magn. Reson. Spectrosc. 2004, 45, 53-108.

[72] van Wüllen, L; Tricot, G.; Wegner, S. An advanced NMR protocol for the structural characterization of aluminophosphate glasses. Solid State Nucl. Magn. Reson. 2007, 32, 44-52.

[73] Kanellopoulos, J.; Freude, D.; Kentgens, A. A practical comparison of MQMAS techniques. Solid State Nucl. Magn. Reson. 2007, 32, 99-108. 